University of Wollongong

Research Online

Faculty of Engineering and Information

Faculty of Engineering and Information

Sciences - Papers: Part A

Sciences

$1-1-2015$

Behaviour of perforated GFRP tubes under axial compression

Weiqiang Wang

University of Wollongong,ww674@uowmail.edu.au

M Neaz Sheikh

University of Wollongong, msheikh@uow.edu.au

Muhammad N. S Hadi

University of Wollongong, mhadi@uow.edu.au

Follow this and additional works at: https://ro.uow.edu.au/eispapers

Part of the Engineering Commons, and the Science and Technology Studies Commons

Research Online is the open access institutional repository for the University of Wollongong. For further information contact the UOW Library: research-pubs@uow.edu.au 


\title{
Behaviour of perforated GFRP tubes under axial compression
}

\begin{abstract}
This study investigates the influences of various parameters on the behaviour of perforated Glass Fibre Reinforced Polymer (GFRP) tubes under axial compression. A total of 15 GFRP tubes with and without perforations were tested under axial compression. All the GFRP tubes were divided into two groups: 12 tubes with $89 \mathrm{~mm}$ outer diameter and $6 \mathrm{~mm}$ wall thickness and 3 tubes with $183 \mathrm{~mm}$ outer diameter and $8 \mathrm{~mm}$ wall thickness. The influences of hole diameter, vertical hole spacing, tube diameter, perforation pattern, transverse hole spacing, and hole reinforcement on the axial compressive behaviour of perforated GFRP tubes were experimentally investigated. Considerable decreases in the axial stiffness, axial critical load, and axial deformation capacity of perforated GFRP tubes have been observed. The hole diameter, tube diameter, perforation pattern, and transverse hole spacing significantly influence the axial compressive behaviour of perforated GFRP tubes. However, the influences of vertical hole spacing and hole reinforcement have been observed not significant. Design-oriented equations for the prediction of the axial stiffness, axial critical load and axial deformation capacity of perforated GFRP tubes under axial compression have been proposed. The proposed equations have been found to be in good agreement with experimental results and can be used for the reliable design of perforated GFRP tubes.
\end{abstract}

\section{Disciplines}

Engineering | Science and Technology Studies

\section{Publication Details}

Wang, W., Sheikh, M. Neaz. \& Hadi, M. N. S. (2015). Behaviour of perforated GFRP tubes under axial compression. Thin-Walled Structures, 95 88-100. 


\section{Behaviour of perforated GFRP tubes under axial compression}

(20)

\author{
School of Civil, Mining and Environmental Engineering, University of Wollongong, \\ NSW 2522, Australia \\ Weiqiang Wang, M. Neaz Sheikh and Muhammad N.S. Hadi*
}




\section{Behaviour of perforated GFRP tubes under axial compression}

31 Abstract: This study investigates the influences of various parameters on the behaviour of perforated Glass Fibre Reinforced Polymer (GFRP) tubes under axial compression. A total of 15 GFRP tubes with and without perforations were tested under axial compression. All the GFRP tubes were divided into two groups: 12 tubes with $89 \mathrm{~mm}$ outer diameter and $6 \mathrm{~mm}$ wall thickness and 3 tubes with 183 $\mathrm{mm}$ outer diameter and $8 \mathrm{~mm}$ wall thickness. The influences of hole diameter, vertical hole spacing, tube diameter, perforation pattern, transverse hole spacing, and hole reinforcement on the axial compressive behaviour of perforated GFRP tubes were experimentally investigated. Considerable decreases in the axial stiffness, axial critical load, and axial deformation capacity of perforated GFRP tubes have been observed. The hole diameter, tube diameter, perforation pattern, and transverse hole spacing significantly influence the axial compressive behaviour of perforated GFRP tubes. However, the influences of vertical hole spacing and hole reinforcement have been observed not significant. Design-oriented equations for the prediction of the axial stiffness, axial critical load and axial deformation capacity of perforated GFRP tubes under axial compression have been proposed. The proposed equations have been found to be in good agreement with experimental results and can be used for the reliable design of perforated GFRP tubes.

Keywords: GFRP; Tube; Perforation; Axial compression; Design-oriented equations. 
54 Perforated GFRP tubes with multiple holes have been tested under axial compression.

55 Influences of different parameters on behaviour of perforated GFRP are investigated.

56 Design equations are developed to predict the capacity of perforated GFRP tubes.

57

58

59

60

61

62

63

64

65

66

67

68

69

70

71

72 


\section{Introduction}

74 Cylindrical shells are widely used in aircrafts, pipeline transportation systems, automobiles, civil engineering structures, and submarine structures. In many cases, holes need to be drilled on the cylindrical shells to meet design requirement (e.g., access port in an aircraft). Due to the presence of holes, the continuous distributions of stress and strain within the shells are interrupted, which leads to obvious stress concentrations around the holes. Therefore, significant performance deterioration of the perforated cylindrical shells can be expected under axial compressive loading. Few studies investigated the influence of perforation on the axial compressive behaviour of isotropic cylindrical shells [1-9]. Gupta et al. [4] performed axial compression tests on perforated mild steel and aluminium round tubes. The deformation of the perforated tubes was found to be initiated at the location of the perforation. Also, the peak load required for the collapse of perforated tubes under axial compression was found to be significantly less than that required for intact tubes. Starnes [5] experimentally and analytically investigated the effect of one circular hole on the buckling of thin seamless electroformed copper cylindrical shells under axial compression. Shell buckling was found to be dependent on a parameter proportional to the hole radius divided by the square root of the product of the shell radius and thickness. Jullien and Liman [6] investigated the effect of hole shapes (square, rectangular, and circular), hole dimensions (axial and circumferential sizes and diameter), and hole location on the buckling behaviour of cylindrical sheet metal shells under axial compression. The axial critical load was found to be sensitive to the circumferential size of the hole. The position of the hole along the longitudinal axis of the shell did not change the critical load. Han et al. [7] carried out numerical investigations to examine the influences of square holes with various sizes and locations on the response of thin and moderately thick aluminium cylindrical shells under axial compression. The location and the size of the square holes significantly influenced the performance of the shells. Few studies also investigated the axial compressive behaviour of perforated isotropic cylinders with reinforced holes [2, 3, 10]. 
Nowadays, fibre reinforced polymer (FRP) composites have been used to replace traditional isotropic materials in many engineering applications due to the advantages of high strength and stiffness to weight ratio and corrosion resistance. One such application is to use pultruded FRP tube in the construction of bridges and boardwalks [11] where holes are needed to be drilled onto the pultruded FRP tubes to assemble different components [12]. While the axial compressive behaviour of isotropic perforated cylindrical shell is well understood, the performance of perforated composite cylindrical shell under axial compression has not yet been adequately investigated. Only few studies were conducted on the perforated composite cylindrical shells [13-18]. Hilburger et al. [13] studied the behaviour of composite cylindrical shells with rectangular holes under axial compression. The effects of hole size and laminate properties on the axial compressive behaviour of perforated composite shell were investigated. The response under axial compression was found to be strongly influenced by the local displacements and internal load distribution near the holes. The local displacements and internal load distributions were affected by the size of the holes, material properties, and imperfections in the shell. Mark and James [17] studied the response of thin-walled composite cylindrical shells with unreinforced and reinforced square holes under axial compression. Local buckling occurred due to a localized nonlinear coupling between local deformations and in-plane destabilizing compression stresses near holes. The buckling load of the shell increased with the addition of reinforcement around the hole. Taheri-Behrooz et al. [18] experimentally and numerically studied the response of perforated composite tubes subjected to axial compressive loading. It was reported that the intact and perforated tubes showed similar instability mode shapes under axial compressive loading. However, the axial critical load and global stiffness of the perforated tubes were found to be significantly lower.

The use of FRP composites to strengthen reinforced concrete structures has been widely studied in the last two decades [19-23]. Recently, Wang et al. [24] and Hadi et al. [25] proposed a new reinforcing scheme named FRP tube reinforced concrete columns in which perforated Glass Fibre Reinforced Polymer (GFRP) tubes $(R / t=7.5 ; R$ is the radius and $t$ is the thickness of the FRP tube) with multiple holes were placed into the concrete columns to provide reinforcement in both longitudinal 
and transverse directions. For the successful and wide application of FRP tube reinforced concrete columns, axial compressive behaviour of perforated GFRP tubes needs to be extensively studied. However, most of previous studies only investigated perforated cylindrical shells with one or two holes $[1-4,7-10,16,17]$ and were mainly focused on the buckling behaviour of perforated thin cylindrical shells with $R / t>20[1-4,6,13,14,16,17]$. None of the above-mentioned studies provided sufficient information on the performance of perforated GFRP tubes $(R / t<20)$ with multiple holes throughout the tubes under axial compression. Considering limited experimental investigation results, an experimental program was carried out to investigate the axial compressive behaviour of perforated GFRP tubes. The influences of different parameters on the performance of perforated GFRP tubes under axial compression have been investigated (Section 2 and Section 3). Moreover, design-oriented equations have been developed to predict the axial stiffness, axial critical load and axial deformation capacity of perforated GFRP tubes under axial compression (Section 4).

\section{Experimental program}

A total of 15 GFRP tubes with and without perforations were tested under axial compression in the High Bay Civil Engineering Laboratory at the University of Wollongong. All GFRP tubes were divided into two groups: Group A contains 12 GFRP tubes with $89 \mathrm{~mm}$ outer diameter and $6 \mathrm{~mm}$ wall thickness and Group B contains 3 GFRP tubes with $183 \mathrm{~mm}$ outer diameter and $8 \mathrm{~mm}$ wall thickness (Fig. 1). The height of Group A GFRP tubes was $260 \mathrm{~mm}$, while the height of Group B GFRP tubes was $185 \mathrm{~mm}$. For Group A GFRP tubes, the influences of hole diameter, vertical hole spacing, perforation pattern, transverse hole spacing, and hole reinforcement on the axial compressive behaviour of perforated GFRP tubes were investigated. For Group B GFRP tubes, the influence of hole diameter was investigated. The influence of tube diameter was investigated by comparing test results of Group A and Group B GFRP tubes. 
152 Group A GFRP tubes were manufactured by Wagners Composite Fibre Technology (CFT) based in 153 Toowoomba, Queensland, Australia [26]. Group B GFRP tubes were manufactured by Exel 154 Composites Australia based in Boronia, Victoria, Australia [27]. The GFRP tubes were pultruded tubes made from vinyl ester resin systems with E-glass fibre. According to the information provided by the manufacturer, Type A pultruded GFRP tubes had an overall E-glass fibre content of 76\%.

157 Starting from the exterior of the tube wall, the stacking sequence of the laminates was in the form of $\left[0 \%+45^{\circ} / 0^{\circ} /-45^{\circ} / 0^{\circ} /-45^{\circ} / 0^{\circ} / 45^{\circ} / 0^{\circ}\right]$, where the $0^{\circ}$ coincided with the longitudinal axis of the tube. The thickness of each ply was the same. The value of $D_{11}$ in the bending stiffness matrix [D] for Type A GFRP tubes' laminates was 586 GPa- $\mathrm{mm}^{3}$. The laminate stacking sequence of Type B pultruded GFRP tube was not available due to commercial confidentiality of the manufacturer. The mechanical properties of GFRP tubes provided by the manufacturers are listed in Table 1. It can be seen from Table 1 that the ultimate tensile strength, ultimate compressive strength, and elastic modulus in the longitudinal direction are much higher than the ultimate tensile strength, ultimate compressive strength and elastic modulus in the transverse direction, respectively. The higher values in the longitudinal direction can be explained by the fact that a vast proportion of the glass fibres were aligned along the longitudinal direction of the GFRP tubes during the pultrusion process.

\subsection{Test Parameters}

The influences of hole diameter (15 mm and $25 \mathrm{~mm}$ ), vertical hole spacing (40 mm, $60 \mathrm{~mm}$ and 100 $\mathrm{mm}$ ), tube diameter (89 $\mathrm{mm}$ and $183 \mathrm{~mm}$ outer diameter), perforation patterns, transverse hole spacing, and hole reinforcement on the axial compressive behaviour of perforated GFRP tubes were investigated in this experimental program. Two different perforation patterns (axially perforated tubes have been designated as APT and diagonally perforated tubes have been designated as DPT) were investigated, as shown in Fig. 2 (a) and (b). The transverse hole spacing was varied by changing the number of holes around the transverse direction of the tubes ( 3 and 4 holes). For perforated GFRP 
tubes with hole reinforcement, 3 layers of Carbon Fibre Reinforced Polymer (CFRP) sheet were wrapped around holes. Different reinforcement configurations were applied for APT and DPT tubes. The detailed configurations are shown in Fig. 2 (c) and (d).

\subsection{Test specimens}

\subsubsection{Description of test specimens}

The details of the GFRP tubes are given in Table 2. The labelling of GFRP tubes has been carried out as: (a) “A” and “B” are used to identify Group A GFRP tubes and Group B GFRP tubes, respectively; (b) "I” indicates intact GFRP tubes without perforation; (c) for perforated GFRP tubes, "D” and the number afterwards indicate the diameter of the hole in $\mathrm{mm}$, "V" and the number afterwards indicate the vertical hole spacing in mm, " $\mathrm{T}$ " and the number afterwards indicate the number of holes around transverse direction; (d) "LW" represents that the GFRP tube was laterally wrapped with CFRP; (e) “APT” represents axially perforated GFRP tube and (f) "DPT” represents diagonally perforated GFRP tube.

\subsubsection{Procedure of tube perforation}

Before perforation, the exact locations of the holes were marked. Afterwards, a drill press machine with a circular drill bit was used to perforate the tubes. Gloves and mask were worn to get protected from harmful fibres during the perforation process. A water spray bottle was used to wash away any waste material. For GFRP tubes wrapped with CFRP, three layers of CFRP were laterally wrapped before tube perforation. Prior to the wrapping of CFRP, the surface of GFRP tube was cleaned to remove all the dust that may affect the wrapping quality. The 105 epoxy resin and 206 slow hardener manufactured by West System were used in this study [28]. A mixture of epoxy resin and hardener at a ratio of 5:1 was used as the adhesive. The CFRP was wrapped onto the GFRP tube manually using a wet lay-up method. No tension force was applied during the wrapping process. Before the wrapping of the first layer of CFRP, the adhesive was spread onto the surface of the GFRP tube. After the first 
layer of CFRP was wrapped, the adhesive was spread onto the first layer of CFRP and the second layer was continuously wrapped. The third layer of CFRP was wrapped in a similar manner. A $70 \mathrm{~mm}$ overlap was maintained to prevent the premature debonding of CFRP. The epoxy resin was then left to cure at room temperature for seven days.

\subsection{Instrumentation and test procedure}

Denison $5000 \mathrm{kN}$ testing machine was used for testing all the GFRP tubes. Before testing, a horizontal level was used to adjust the bottom steel plate to ensure that the surface of the bottom steel plate was horizontal. Afterwards, the tube was placed onto the bottom steel plate to check whether there was any misalignment between the tube end and the bottom steel plate. If no misalignment was observed, then the tube end was considered to be horizontal and parallel to the bottom steel plate. However, if a slight misalignment was observed, the tube end was slightly smoothed using a belt sander until the misalignment was removed. The same procedure was applied to the other tube end. Afterwards, a vertical level was used to ensure that both the tube ends were perpendicular to the longitudinal axis of the tube. When the tube ends were horizontal and perpendicular to the longitudinal axis of the tube, and the surfaces of steel plates were horizontal, then the load can be considered to be applied in a purely axial manner. Axial deformations were measured using two Linear Variable Differential Transducers (LVDTs) mounted at the opposite corners of the steel plate. The load and deformation data were collected using an electronic data-logger at 2 second intervals. The test (displacement controlled) was conducted at a rate of $0.3 \mathrm{~mm} / \mathrm{min}$. All GFRP tubes were tested until failure. The test setup and instrumentation are shown in Fig. 3.

In order to prevent the premature failure at the tube end, a specially designed test fixture was manufactured and used. The test fixture was composed of a steel flange and a steel sleeve, as shown in Fig. 4 (a) and (b). By combining these two components together, a groove can be developed to constrain the tube ends (Fig. 4(c)). In order to prevent the upper steel sleeve from slippage, the upper 
steel sleeve was fixed onto the upper steel flange using three bolts (Fig. 4 (d)). The engineering drawings of these two components are shown in Fig. 5. After the test fixture was capped onto the tube ends, the same procedures mentioned above were followed to ensure that the load was applied in a purely axial manner.

\section{Experimental results and analysis}

\subsection{Failure modes of GFRP tubes}

All tested GFRP tubes failed in a brittle manner because of the non-ductile characteristics of the fibres and epoxy resin. For intact Group A GFRP tube “A-I” without capping the test fixture, failure was caused due to the stress concentration phenomenon at the tube end, which resulted in a lower compressive strength than the actual compressive strength (Fig. 6 (a)). However, by capping the test fixture onto the tube ends, a global collapse was observed for Tube "A-I” (Fig. 6 (b)). Therefore, it is evident that by using the developed test fixture, the stress concentration at the tube ends can be effectively eliminated and the actual compressive strength can be obtained. For intact Group B GFRP tube "B-I”, global collapse was observed after the axial compressive strength was reached. The failure of perforated GFRP tubes was initiated with crack formation around the holes due to severe local stress concentration. Initially cracking noise was heard. The cracking noise increased with the increase of axial compressive load. The crack formation was followed by a sudden drop of the axial compressive load, with the splitting of the fibres around holes accompanied by a loud noise. After splitting, the fibres were bent and curled outwards, extensively delaminated, and fractured transversely and longitudinally around the holes. It is noted that longitudinal rupture are more serious than transverse rupture. This is mainly because GFRP tubes were manufactured by pultrution with majority of fibres aligned in the longitudinal direction. The failure modes of perforated GFRP tubes depend largely on the perforation patterns. For axially perforated GFRP tubes, rupture was observed around holes at the same height (Fig. 6 (c)). For diagonally perforated GFRP tubes, the tubes failed 
due to crack development in the middle of three neighbouring holes (Fig. 6 (d)). For perforated GFRP tubes with reinforced holes, the failure modes were similar to those of perforated GFRP tubes without hole reinforcement (Fig. 6 (e)).

\subsection{Axial load-axial deformation behaviour of GFRP tubes}

A summary of the test results which include axial stiffness ratio (axial stiffness ratio between perforated tubes and intact tubes), axial critical load ratio (axial critical load ratio between perforated tubes and intact tubes), and axial deformation ratio (axial deformation ratio between perforated tubes and intact tubes) are given in Table 3. The axial stiffness for intact Group A GFRP tube was 166 $\mathrm{kN} / \mathrm{mm}$, while the axial stiffness for intact Group B GFRP tube was $700 \mathrm{kN} / \mathrm{mm}$. The axial load-axial deformation diagrams of both intact and perforated GFRP tubes are presented in the following sections. Both intact and perforated GFRP tubes show linear axial load-axial deformation behaviour until the sudden collapse of the tubes. Considerable decreases in the axial stiffness, axial critical load, and axial deformation capacity were observed due to the perforation, as explained below.

\subsubsection{Influence of hole diameter}

Fig. 7 illustrates the axial load-axial deformation behaviour of intact GFRP tube and perforated GFRP tubes with different hole diameters. The effect of hole diameter was investigated by drilling $15 \mathrm{~mm}$ and $25 \mathrm{~mm}$ diameter holes while keeping the other parameters constant. In Fig. 7(a), for perforated GFRP tube “A-D25-V60-T4 (APT) ” (with 25 mm diameter holes), 29.1\%, 49.1\%, and 27.8\% reductions in the axial stiffness, axial critical load, and corresponding deformation, respectively, are observed compared to those of intact GFRP tube. For perforated GFRP tube “A-D15-V60-T4 (APT)” (with $15 \mathrm{~mm}$ diameter holes), 18.2\%, 36.1\%, and 21.6\% reductions are observed in the axial stiffness, axial critical load, and corresponding deformation, respectively, compared to those of intact GFRP tube. In Fig. 7 (b), the reductions of axial stiffness, axial critical load, and corresponding deformation are $13.6 \%$, 28.2\%, and 17.1\%, respectively, for perforated GFRP tube "B-D25-V60-T3 (APT)" (with 
$25 \mathrm{~mm}$ diameter holes), while the corresponding reductions are $9.1 \%, 14.8 \%$, and $6.3 \%$, respectively, for perforated GFRP tube "B-D15-V60-T3 (APT)” (with $15 \mathrm{~mm}$ diameter holes). Therefore, by reducing the hole diameter, the axial stiffness, axial critical load, and axial deformation capacity could be significantly increased. These results are slightly different from the results reported in TaheriBehrooz et al. [18]. In Ref. [18], hole diameters of $2.5 \mathrm{~mm}, 10 \mathrm{~mm}$, and $15 \mathrm{~mm}$ were used to numerically investigate the influence of hole diameter on the load carrying capacity of perforated tubes. Since the hole diameters in Ref. [18] were relatively small compared to the diameter of the tubes (107.3 mm inner diameter), the influence of the hole diameter was not significant. However, the influence of hole diameter on the performance of perforated GFRP tubes under axial compression cannot be neglected especially for perforated GFRP tubes with larger holes.

The variation of local deformation was analysed by investigating the strain distributions at representative locations for perforated GFRP tube “A-D25-V60-T4 (APT)”. In this study, the strain gauges were attached onto locations away from the perforations to investigate how perforation can influence the strain distributions at locations away from the perforations. Two representative locations were selected. The first location (Point A) was in the middle of two vertical neighbouring holes and the second location (Point B) was in the intact part of GFRP tube, as shown in Fig. 8 (a). Fig. 8 (b) shows the distribution of strains. It can be seen from Fig. 8 (b) that the axial strain at intact part was two times of hoop strain at intact part (Point B). The axial and hoop strains obtained at the intact part (Point B) were 10 and 5 times of those of axial and hoop strains obtained in between two vertical neighbouring holes (Point A), respectively. Therefore, it is evident that the major part of the tubes that carries the axial compressive load is the intact vertical segment of the tube without any holes. This observation can be used to explain that perforated tubes with smaller hole diameter have higher axial critical load under axial compression. Moreover, it is reasonable to expect that when the perforated tubes were subject to internal pressure, the major parts in resisting the hoop tensile load are the intact segments in the hoop direction of the tube. 
The axial load-axial deformation diagrams shown in Fig. 9 are used to illustrate the influence of vertical hole spacing on the axial compressive behaviour of perforated GFRP tubes. Vertical hole spacing of $60 \mathrm{~mm}$ and $100 \mathrm{~mm}$ were investigated. All other parameters were kept constant. In Fig. 9 (a), the increases in the axial stiffness, axial critical load, and corresponding axial deformation with the increase in the vertical hole spacing from $60 \mathrm{~mm}$ (A-D25-V60-T4 (APT)) to $100 \mathrm{~mm}$ (A-D25V100-T4 (APT)) are 6.8\%, 6.3\%, and 6.2\%, respectively. Similarly, in Fig. 9 (b), the increases in the axial stiffness, axial critical load, and corresponding deformation with the increase in the vertical spacing from 60 mm (A-D15-V60-T3 (APT)) to 100 mm (A-D15-V100-T3 (APT)) are 4.1\%, 4.8\%, and 5.6\%, respectively. Therefore, by increasing the vertical hole spacing, the axial stiffness, axial critical load, and axial deformation capacity can be increased. However, the increase is not highly significant (within 4\%-7\%).

The strain distributions between two vertical holes as well as at the intact part were investigated for perforated GFRP tube “A-D25-V100-T4 (APT)”. Fig. 10 (a) shows the layout of strain gauge and Fig. 10 (b) shows the axial strain distributions. It can be seen from Fig. 10 (b) that the axial strain at Point B is only one third of the axial strain at Point A. This indicates that the closer the distance between holes, the less the axial strain can be obtained. Both the axial strains between two vertical holes (Point A and Point B) are much less than the axial strain at the intact part (Point C). Therefore, the vertical part between two neighbouring vertical holes contributes little to the performance of perforated GFRP tube under axial compression. It is noted that the axial strains obtained between two vertical holes increase nonlinearly with the axial load. This nonlinear behaviour is more obvious for Point B which is closer to the holes. It might be due to the fact that the fibres around holes were cut and damaged because of the perforation, which disturbed the linear properties of fibre bundles. Therefore, it can be reasonably argued that perforated GFRP tubes with a relatively small vertical hole spacing may not 
cause significant performance degradation under axial compression. However, this argument may not applicable for perforated GFRP tubes with very small vertical hole spacing because the minor cracks around closely spaced neighbouring vertical holes can easily develop into a fatal crack, which may result in an earlier tube failure.

\subsubsection{Influence of tube diameter}

The influence of tube diameter is investigated by comparing test results obtained from Group A and Group B GFRP tubes. The major difference between Group A and Group B tubes was the tube diameter (89 mm and $183 \mathrm{~mm}$ outer diameter). Fig. 11 (a) and (b) illustrate axial load-axial deformation diagrams of perforated GFRP tubes with different tube diameters. For comparison purpose, the axial load and axial deformation of GFRP tubes are normalized with respect to the axial critical load and corresponding deformation of intact GFRP tubes, respectively. In Fig. 11 (a), for Tube "A-D25-V60-T3 (APT)", the perforation leads to the reductions of 23.3\%, 43.4\%, and 25.9\% in the axial stiffness, axial critical load, and corresponding deformation, respectively. However, the reductions are 13.6\%, 28.2\%, and 17.1\%, respectively, for Tube “B-D25-V60-T3 (APT)”. Similarly, in Fig. 11 (b), reductions of $11.5 \%, 30.1 \%$, and $20.6 \%$ in the axial stiffness, axial critical load, and corresponding deformation are observed for Tube "A-D15-V60-T3 (APT)", and the corresponding reductions for Tube "B-D15-V60-T3 (APT)" are 9.1\%, 14.8\%, and 5.3\%. Therefore, it is clear that when other parameters are kept constant, increasing the tube diameter can improve the performance of perforated GFRP tubes under axial compression.

\subsubsection{Influence of perforation pattern}

Fig. 12 compares axial load-axial deformation behaviour between axially perforated GFRP tube (APT) and diagonally perforated GFRP tube (DPT). In Fig. 12 (a), for diagonally perforated tube “A-D25V60-T3 (DPT)”, the axial stiffness, axial critical load, and corresponding deformation are 93.3\%, 73.4\%, and 78.6\%, respectively, of those of axially perforated tube “A-D25-V60-T3 (APT)". 
Furthermore, for tube “A-D25-V40-T4 (DPT)” in Fig. 12 (b), the axial stiffness, axial critical load, and corresponding deformation are $108.6 \%, 89.9 \%$, and $83.2 \%$, respectively, compared to those of tube "A-D25-V40-T4 (APT)". Interestingly, even though more holes were perforated on axially perforated tubes, better performance than diagonally perforated tubes under axial compression is observed. This may be explained that for diagonally perforated GFRP tubes, the cracks between neighbouring holes are easier to develop into a fatal crack, and hence the rupture is more likely to occur at an early stage. Based on the above investigation, it is recommended that perforated GFRP tubes with axial perforation pattern should be selected in order to improve the axial compressive behaviour.

\subsubsection{Influence of transverse hole spacing}

Fig. 13 illustrates the influence of transverse hole spacing on the axial compressive behaviour of perforated GFRP tubes. The variation of transverse hole spacing was investigated by changing the number of holes around tube transverse direction. The less the hole numbers around tube transverse direction, the larger the transverse spacing between holes. The perforated tubes with three and four holes around tube transverse direction were tested under axial compression while the other parameters were kept constant. Fig. 13 (a) and (b) illustrate that the axial stiffness and the axial critical load increases significantly with the increase of transverse hole spacing. However, the corresponding deformations at axial critical load do not show significant differences. Compared to the test results presented in Sections 3.2.1-3.2.5, it can be inferred that increase of perforation around tube transverse direction can lead to a significant decrease in the performance of perforated GFRP tube under axial compression. However, increase of perforation around tube longitudinal direction may not significantly influence the performance. Therefore, it is recommended that with a fixed perforation area throughout the tube, the perforation along transverse direction can be reduced while the perforation along the longitudinal direction can be increased in order to improve the axial compressive behaviour of perforated GFRP tubes. 


\subsubsection{Influence of hole reinforcement}

Reinforcement can be applied around holes so that the axial compressive behaviour of perforated cylindrical shells may be improved [2, 3, 10, 19, 20]. In this study, 3 layers of CFRP sheet were wrapped around the holes to investigate whether this type of reinforcement could be effective in improving the performance of perforated GFRP tubes under axial compression. Fig. 2 (c) and (d) provide the specific layout of reinforcement for both axially and diagonally perforated GFRP tubes. Fig. 14 shows the axial load-axial deformation behaviour of perforated tubes with reinforced or unreinforced holes. Both reinforced and unreinforced perforated tubes show similar behaviour under axial compression. The performance improvement is not significant for perforated tubes with reinforced holes. By wrapping CFRP sheet in this manner cannot contribute to increase the value of $\mathrm{D}_{11}$ in the bending stiffness matrix [D] for the laminates of the tube. Nevertheless, it may be reasonable to expect that CFRP wrapping around holes would be effective for perforated GFRP tubes subjected to internal pressure for which significant transverse tensile strain may occur.

\section{Development of design-oriented equations}

This section aims to develop design-oriented equations to characterise the axial stiffness, axial critical load, and axial deformation capacity of perforated GFRP tubes under axial compression. The equations contain the main parameters that influence the axial compressive behaviour of perforated GFRP tubes. The reliability of the proposed equations has been verified by the experimental test. For the development of design-oriented equations, few basic assumptions are adopted: (1) the major parts in resisting the axial compressive load are the vertical intact segment of the perforated GFRP tubes; (2) the influence of vertical hole spacing on the axial compressive behaviour is not significant; and (3) the axial deformation capacity is decreased because of the perforation. All the assumptions are in accordance with the experimental observations presented in Section 3. 
411 Two parameters are introduced herein. The first parameter is perforation ratio, which is defined as the ratio between the sum of perforation length around tube transverse direction and the perimeter of the

413 GFRP tube:

$$
v=\frac{n d}{\pi\left(D_{i}+t\right)}
$$

414 where $v$ is perforation ratio; $D_{i}, d$, and $t$ are the inner diameter, hole diameter, tube thickness of

415 GFRP tube, respectively; and $n$ is the number of holes around tube transverse direction. The less is 416 the perforation ratio $v$, the more is the intact vertical segment without holes for perforated GFRP 417 tubes.

A parameter $\mu$ has been used to characterise the behaviour of perforated cylindrical shells under axial compression [2, 4]. In this study, the parameter $\mu$ is used to investigate the axial compressive behaviour of perforated GFRP tubes. Since $\mu$ is only suitable for perforated tubes with one hole, in order to make $\mu$ suitable for perforated tubes with multiple holes, Equation (2) has been proposed herein:

$$
\mu=\frac{n \cdot a}{\sqrt{R t}}
$$

where $a$ is the radius of the hole and $R$ is the radius of the tube.

Taheri-Behrooz et al. [18] investigated the axial compressive behaviour of perforated GFRP tubes. Details of the test data in Taheri-Behrooz et al. [18] can be found in Table 4. The parameters in the database include the radius of GFRP tubes $R$, tube thickness $t$, perforation ratio $v$, parameter $\mu$, axial 
stiffness ratio $\kappa$, axial critical load ratio $\eta$, and axial deformation ratio $\lambda$. It should be noted that all

431 perforated tubes were diagonally perforated GFRP tubes in Taheri-Behrooz et al. [18].

434 Based on Assumption (1), the axial stiffness of perforated GFRP tube is equal to the axial stiffness of 435 intact vertical segment of perforated GFRP tube without holes. Therefore, the axial stiffness ratio $\kappa$ 436 between perforated GFRP tube and intact GFRP tube can be estimated according to Equation (3):

$$
\kappa=1-v=\frac{\pi\left(D_{i}+t\right)-n d}{\pi\left(D_{i}+t\right)}
$$

437 Fig. 15 shows the axial stiffness ratio versus the perforation ratio from this study and Taheri-Behrooz 438 et al. [18]. A linear relationship exists between the axial stiffness ratio and perforation ratio. Close agreements between the test data and prediction results can be observed in Fig. 15. In addition, by

440 using the proposed equation, a conservative prediction of axial stiffness ratio can be obtained. This 441 may be due to the assumption that only the vertical intact part of the perforated GFRP tube carries the 442 load. Therefore, the contribution from the vertical perforated part of GFRP tube is neglected.

443 The accuracy of the prediction is quantified using two statistical indicators: mean square error (MSE) 444 and average absolute error (AAE). These two indicators are determined by Equation (4) and Equation 445 (5), respectively:

$$
\begin{aligned}
M S E & =\frac{\sum_{i=1}^{N}\left(\frac{\operatorname{pre}_{i}-\exp _{i}}{\exp _{i}}\right)^{2}}{N} \\
A A E & =\frac{\sum_{i=1}^{N}\left|\frac{\operatorname{pre}_{i}-\exp _{i} \mid}{\exp }\right|}{N}
\end{aligned}
$$

446 where pre is the prediction result, exp is the experimental result, and $N$ is the total number of dataset. 
447 The values of mean square error (MSE) and average absolute error (AAE) are only $0.4 \%$ and $4.7 \%$,

448 respectively. Hence, the proposed equation can predict the experimental behaviour with very good 449 accuracy.

451 Axially perforated GFRP tubes and diagonally perforated GFRP tubes performed differently under

452 axial compression. Therefore, it is not appropriate to adopt the same equations to predict the axial critical load as well as axial deformation capacity of perforated GFRP tubes with different perforation patterns. It has been proved in this study that axially perforated GFRP tubes performed better than diagonally perforated GFRP tubes under axial compression. Therefore, experimental results on axially perforated GFRP tubes are used for the prediction of axial critical load as well as axial deformation capacity of the perforated GFRP tubes. Experimental results on diagonally perforated GFRP tubes (DPT) are excluded in the following section.

\subsection{Proposal for axial critical load ratio, $\eta$}

Due to the complex mechanism caused by perforation, few theoretical analyses have been conducted to predict the axial critical load of perforated cylindrical shells under axial compression $[3,5,6]$. Based on the analysis of available experimental results, it can be found that both the perforation ratio and parameter $\mu$ will significantly affect the axial critical load of perforated GFRP tubes. The following equations are proposed based on the regression of existing experimental data to predict the axial critical load ratio of axially perforated GFRP tubes (APT) using perforation ratio and parameter $\mu$ :

$$
\begin{aligned}
& \eta=0.953-1.226 v \\
& \eta=0.967-0.158 \mu
\end{aligned}
$$

Fig. 16 shows the axial critical load ratio versus the perforation ratio $v$ and Fig. 17 shows the axial critical load ratio versus the parameter $\mu$. It can be seen that the axial critical load decreased with the 
increase of perforation ratio $v$ (parameter $\mu$ ). Hence, a linear relationship can be established. The

471

472

473

474

476

478 comparison of mean square error (MSE) and average absolute error (AAE) for Equations (6-7) has been shown in Fig. 18. It can be seen that the equations show good agreement with experimental results. Both the mean square error (MSE) and average absolute error (AAE) of Equation (6) were higher than those of Equation (7), which indicates that it is necessary to take the tube thickness into consideration for the more accurate prediction of the axial critical load of perforated GFRP tubes. Nevertheless, for simplicity, Equation (6) can also be used with a satisfactory accuracy.

\subsection{Proposal for axial deformation ratio, $\lambda$}

Previously, attention was focused on the prediction of axial critical load of perforated cylindrical shells under axial compression, and none of the previous studies provided information for the prediction of axial deformation capacity of perforated cylindrical shells. Equations (8) and (9) are proposed to predict the axial deformation capacity for the axially perforated GFRP tubes (APT) based on a regression analysis of experimental results using perforation ratio $v$ and parameter $\mu$ :

$$
\begin{aligned}
& \lambda=0.954-0.590 v \\
& \lambda=0.961-0.076 \mu
\end{aligned}
$$

Fig. 19 shows the axial deformation ratio versus perforation ratio, and Fig. 20 shows the axial deformation ratio versus parameter $\mu$. A good correlation has been obtained between the predictions and experimental results. The comparison of mean square error (MSE) and average absolute error (AAE) for Equations (8-9) can be seen in Fig. 18. Similar to the prediction of axial critical load, the prediction accuracy of axial deformation ratio is higher for equation developed based on parameter $\mu$ (Equation 9). As a result, in order to get more accurate prediction, the influence of tube thickness should be taken into consideration. 
In general, even though satisfactory prediction can be obtained by these equations, more test data is needed for perforated GFRP tubes with larger perforation ratio as well as with different tube thicknesses before proposing more general equations to predict the axial compressive behaviour of perforated GFRP tubes. Such experimental and analytical ingestions are the part of ongoing research projects of the authors.

\section{Conclusions}

This study presents a comprehensive assessment of the parameters that may influence the axial compressive behaviour of perforated Glass Fibre Reinforced Polymer (GFRP) tubes. Based on the experimental investigation, design-oriented equations are developed to predict the axial compressive behaviour of perforated GFRP tubes. The following conclusions can be drawn:

The key parameters controlling the axial compressive behaviour of perforated GFRP tubes are the hole diameter, tube diameter, perforation pattern, transverse hole spacing. By reducing the hole diameter or increasing the tube diameter as well as transverse hole spacing, the axial compressive behaviour of perforated GFRP tubes can be significantly improved. Axially perforated tubes (APT) perform better than diagonally perforated tubes (DPT) under axial compression.

The influences of vertical hole spacing and hole reinforcement on the performance of perforated GFRP tubes under axial compression have been found not significant.

Design-oriented equations are developed for the prediction of axial stiffness, axial critical load and axial deformation capacity of perforated GFRP tubes under axial compression. The accuracies of the equations are verified by two statistical methods: average absolute error (AAE) and mean square error

513 (MSE). The developed design-oriented equations can predict the axial compressive behaviour of 514 perforated GFRP tubes with satisfactory accuracies. 


\section{Acknowledgments}

517 The authors acknowledge the technical officer Mr. Ritchie Mclean, who constructed the test fixture used in the experimental program. The contribution of Mr. Alan Grant for his help in carrying out the experiment is appreciated. The authors also thank Wagners CFT for providing GFRP tubes. The first author acknowledges the China Scholarship Council and the University of Wollongong for supporting his $\mathrm{PhD}$ scholarship.

\section{References:}

524 [1] Tennyson RC. The effect of unreinforced circular cutouts on the buckling of circular cylindrical 525 shells under axial compression. Journal of Engineering for Industry 1968; 90(4): 541-546.

526 [2] Toda, S. Buckling of cylinders with cutouts under axial compression. Experimental Mechanics; 527 23(4): 414-417.

528 [3] Almroth BO, Holmes AM. Buckling of shells with cutouts. Experimental and analysis. International Journal of Solids Structures 1972;8:1057-1071.

[4] Gupta NK,Gupta SK.. Effect of annealing, size and cut-outs on axial collapse behaviour of circular columns. International Journal of Mechanical Sciences 1993; 35(7): 597-613.

532 [5] Starnes JH. Effects of a circular hole on the buckling of cylindrical shells loaded by axial 533 compression. American Institute of Aeronautics and Astronautics 1972;10:1466-72.

534 [6] Jullien JF, Limam A. Effect of openings on the buckling of cylindrical shells subjected to axial 535 compression. Thin-Walled Structures1998;31:187-202.

536 [7] Han H, Cheng J, Taheri F, Pegg N. Numerical and experimental investigations of the response of 537 aluminum cylinders with a cutout subject to axial compression. Thin-Walled Structures 2006;44:254$538 \quad 70$. 
539

540

541

542

543

544

545

546

547

548

549

550

551

552

553

554

555

556

557

558

559

560

561

562

[8] Shariti M, Rokhi MM. Numerical and experimental investigations on buckling of steel cylindrical shells with elliptical cutout subject to axial compression. Thin-Walled Structures 2008;46:1251-61.

[9] Shariati M, Rokhi MM. Buckling of steel cylindrical shells with an elliptical cutout. International Journal of Steel Structures 2010; 10(2): 193-205.

[10] Cervantes JA, Palazotto AN. Cutout reinforcement of stiffened cylindrical shells. Journal of Aircraft 1979; 16 (3): 203-208.

[11] Wagners: Composite Fibre Technologies. 339 Anzac Avenue, Toowoomba, QLD Australia. http://www.wagnerscft.com.au/projects/ (Accessed on June 2015).

[12] Wagners: Composite Fibre Technologies. 339 Anzac Avenue, Toowoomba, QLD Australia. http://www.wagnerscft.com.au/technical/product-guide/ (Accessed on June 2015).

[13] Hilburger MW, Starnes JH, Waas AM. A numerical and experimental study of the response of selected compression-loaded composite shells with cutouts. Proceedings of the 39th AIAA/ASME/ASCE/AHS/ASC Structures, Structural Dynamics, and Materials Conference, Long Beach, CA., AIAA Paper No. 98-1768, 1998.

[14] Hilburger MW, Vicki OB, Michael PN. Buckling behaviour of compression-loaded quasiisotropic curved panels with a circular cutout. International Journal of Solids and Structures 2001; 38: 1495-1522.

[15] Oterkus E, Madenci E, Nemeth MP. Stress analysis of composite cylindrical shells with an elliptical cutout. Journal of Mechanics of Materials and Structures 2007; 2(4): 695-727.

[16] Tafreshi A. Buckling and post buckling analysis of composite cylindrical shells with cutout subjected to internal pressure and axial compression load. International Journal of Pressure Vessels and Piping 2002; 79(5): 351-359.

[17] Mark WH, James HS. Buckling behaviour of compression-loaded composite cylindrical shells with reinforced cutouts. International Journal of Non-linear Mechanics 2005; 40(7): 1005-1021. 
563

564

565

566

567

568

569

570

571

572

573

574

575

576

577

578

579

580

581

582

583

584

585

[18] Taheri-Behrooz F, Esmaeel RA, Taheri F. Response of perforated composite tubes subjected to axial compressive loading. Thin-Wall Structures 2012; 50 (1): 174-181.

[19] Teng JG, Chen JF, Smith ST, Lam L. FRP-strengthened RC structures. Chichester, West Sussex, UK: John Wiley and Sons, 2002.

[20] Hadi MNS. Behaviour of FRP strengthened concrete columns under eccentric compression loading. Composite Structures 2007; 77(1): 92-96.

[21] Hadi MNS, Tran TM. Retrofitting nonseismically detailed exterior beam-column joints using concrete covers together with CFRP jacket. Construction and Building Materials 2014; 63: 161-173.

[22] Hadi MNS, Widiarsa I. Axial and flexural performance of square RC columns wrapped with CFRP under eccentric loading. Journal of Composites for Construction 2012; 16 (6): 640-649.

[23] Hadi MNS, Le TD. Behaviour of hollow core square reinforced concrete columns wrapped with CFRP with different fibre orientations. Construction and Building Materials 2014; 50: 62-73.

[24] Wang WQ, Sheikh MN, Hadi MNS, Lyons B. Behaviour of GFRP tube reinforced concrete columns under axial compression. Proceedings of the Seventh International Conference on FRP Composites in Civil Engineering (CICE 2014), August 20-22, 2014, Vancouver, Canada.

[25] Hadi MNS, Wang WQ, Sheikh MN. Axial compressive behaviour of GFRP tube reinforced concrete columns. Construction and Building Materials 2015; 81:198-207.

[26] Wagners: Composite Fibre Technologies. 339 Anzac Avenue, Toowoomba, QLD Australia. http://www.wagnerscft.com.au/ (Accessed on June 2015).

[27] Exel Composites Australia. 991 Mountain Highway, Boronia, Melbourne, VIC Australia. http://www.exelcomposites.com.au/ (Accessed on June 2015).

[28] West System Inc. 102 Patterson Ave, Bay City, MI, U.S. http://www.westsystem.com/ss/typicalphysical-properties/ (Accessed on June 2015). 
587 Table 1. Mechanical properties of GFRP tubes.

588 Table 2. Test matrix.

589 Table 3. Experimental results.

590 Table 4. Summary of test results.

591

592

593

594

595

596

597

598

599

600

601

602

603

604

605

606 
608 Fig. 1. Intact GFRP tubes

609 Fig. 2. Perforated GFRP tubes

610 Fig. 3. Test set-up and instrumentation

611 Fig. 4. Details of test fixture

612 Fig. 5. Engineering drawings of test fixture

613 Fig. 6. Failure modes of GFRP tubes

614 Fig. 7. Influence of hole diameter on the axial compressive behaviour of perforated GFRP tubes

615 Fig. 8. Strain distribution at different locations of GFRP tube “A-D25-V60-T4 (APT)”

616 Fig. 9. Influence of vertical hole spacing on the axial compressive behaviour of perforated GFRP 617 tubes

618 Fig. 10. Axial strain distribution at different locations of GFRP tube "A-D25-V100-T4 (APT)"

619 Fig. 11. Influence of tube diameter on the axial compressive behaviour of perforated GFRP tubes

620 Fig. 12. Influence of perforation pattern on the axial compressive behaviour of perforated GFRP tubes

621 Fig. 13. Influence of transverse hole spacing on the axial compressive behaviour of perforated GFRP 622 tubes

623 Fig. 14. Influence of hole reinforcement on the axial compressive behaviour of perforated GFRP tubes

624 Fig. 15. Prediction of axial stiffness ratio from perforation ratio

625 Fig. 16. Prediction of axial critical load ratio from perforation ratio (Axially perforated GFRP tubes)

626 Fig. 17. Prediction of axial critical load ratio from parameter $\mu$ (Axially perforated GFRP tubes)

627 Fig. 18. Error estimates of the proposed design-oriented equations

628 Fig. 19. Prediction of axial deformation ratio from perforation ratio (Axially perforated GFRP tubes) Fig. 20. Prediction of axial deformation ratio from parameter $\mu$ (Axially perforated GFRP tubes) 
Mechanical properties of GFRP tubes.

\begin{tabular}{|c|c|c|c|c|c|c|c|}
\hline \multirow{2}{*}{ Group } & \multicolumn{3}{|c|}{ Ultimate Tensile Strength (MPa) } & \multicolumn{2}{|c|}{ Ultimate Compressive Strength (MPa) } & \multirow{2}{*}{$\begin{array}{c}\text { Shear Strength } \\
\text { (MPa) }\end{array}$} & \multicolumn{2}{|c|}{$\begin{array}{c}\text { Modulus of Elasticity } \\
(\mathrm{GPa})\end{array}$} \\
\cline { 2 - 5 } & Longitudinal & Transverse & Longitudinal & Transverse & & Longitudinal & Transverse \\
\hline A & 650 & 41 & 550 & 104 & 84 & 35.4 & 12.9 \\
\hline B & 450 & 50 & 450 & 80 & 25 & 30 & 10 \\
\hline
\end{tabular}

632 


\begin{tabular}{|c|c|c|c|c|}
\hline GFRP tube & Hole diameter (mm) & $\begin{array}{l}\text { Vertical hole spacing } \\
\text { (mm) }\end{array}$ & $\begin{array}{l}\text { Number of holes around } \\
\text { transverse direction }\end{array}$ & Reinforcement \\
\hline A-I & None & None & None & None \\
\hline A-D25-V40-T4(APT) & 25 & 40 & 4 & None \\
\hline A-D25-V40-T4 (DPT) & 25 & 40 & 4 & None \\
\hline A-D25-V40-T4-LW (DPT) & 25 & 40 & 4 & Yes \\
\hline A-D25-V60-T4 (APT) & 25 & 60 & 4 & None \\
\hline A-D25-V60-T4-LW (APT) & 25 & 60 & 4 & Yes \\
\hline A-D25-V100-T4 (APT) & 25 & 100 & 4 & None \\
\hline A-D25-V60-T3 (APT) & 25 & 60 & 3 & None \\
\hline A-D25-V60-T3 (DPT) & 25 & 60 & 3 & None \\
\hline A-D15-V60-T4 (APT) & 15 & 60 & 4 & None \\
\hline A-D15-V60-T3 (APT) & 15 & 60 & 3 & None \\
\hline A-D15-V100-T3 (APT) & 15 & 100 & 3 & None \\
\hline B-I & None & None & None & None \\
\hline B-D25-V60-T3 (APT) & 25 & 60 & 3 & None \\
\hline B-D15-V60-T3 (APT) & 15 & 60 & 3 & None \\
\hline
\end{tabular}


(Note: “A” and “B” are used to identify Group A GFRP tubes and Group B GFRP tubes, respectively; “I” indicates intact GFRP tubes without perforation; for perforated GFRP tubes, "D" and the number afterwards indicate the diameter of the hole in mm; "V” and the number afterwards indicate the vertical hole spacing in mm; “T” and the number afterwards indicate the number of holes around transverse direction; "LW” represents that the GFRP tube was laterally

652 Table 3.

653 Experimental results.

\begin{tabular}{|l|c|c|c|c|}
\hline \multicolumn{1}{|c|}{ GFRP tube } & Perforation ratio $v$ & $\mu$ & Axial stiffness ratio $\kappa$ & Axial deformation ratio $\lambda$ \\
\hline A-I & 0 & 0 & 1 & 1 \\
\hline A-D25-V40-T4 (DPT) & 0.384 & 3.06 & 0.652 & 0.665 \\
\hline A-D25-V40-T4-LW (DPT) & 0.384 & 3.06 & 0.652 & 0.694 \\
\hline A-D25-V40-T4 (APT) & 0.384 & 3.06 & 0.6 & 0.799 \\
\hline A-D25-V40-T4-LW (APT) & 0.384 & 3.06 & 0.6 & 0.752 \\
\hline A-D25-V60-T4 (APT) & 0.384 & 3.06 & 0.709 & 0.722 \\
\hline A-D25-V60-T4-LW (APT) & 0.384 & 3.06 & 0.688 & 0.469 \\
\hline A-D25-V100-T4 (APT) & 0.384 & 3.06 & 0.758 & 0.734 \\
\hline
\end{tabular}




\begin{tabular}{|l|c|c|c|c|c|}
\hline A-D25-V60-T3 (APT) & 0.288 & 2.295 & 0.767 & 0.741 \\
\hline A-D25-V60-T3 (DPT) & 0.288 & 2.295 & 0.715 & 0.583 \\
\hline A-D15-V60-T4 (APT) & 0.230 & 1.836 & 0.818 & 0.784 \\
\hline A-D15-V60-T3 (APT) & 0.173 & 1.377 & 0.885 & 0.794 \\
\hline A-D15-V100-T3 (APT) & 0.173 & 1.377 & 0.921 & 0.799 \\
\hline B-I & 0 & 0 & 1 & 0.733 \\
\hline B-D15-V60-T3 (APT) & 0.082 & 0.832 & 0.909 & 0.937 \\
\hline B-D25-V60-T3 (APT) & 0.136 & 1.386 & 0.864 & 0.829 \\
\hline
\end{tabular}

654

655

656

657

658

659 
661 Table 4.

662 Summary of test results in Ref. [16].

\begin{tabular}{|c|c|c|c|c|c|c|c|}
\hline No. & $\begin{array}{c}\text { Radius of tubes } \\
R(\mathrm{~mm})\end{array}$ & $\begin{array}{c}\text { Thickness } \\
t(\mathrm{~mm})\end{array}$ & Perforation ratio $v$ & $\mu$ & Axial stiffness ratio $\kappa$ & Axial deformation ratio $\lambda$ & $\begin{array}{c}\text { Axial critical } \\
\text { load ratio } \eta\end{array}$ \\
\hline 1 & 53.15 & 2.2 & 0 & 0 & 1 & 1 & 0.742 \\
\hline 2 & 53.15 & 2.2 & 0.174 & 0.462 & 0.874 & 1 & 0.650 \\
\hline 3 & 53.15 & 1.5 & 0 & 0 & 1 & 0.741 & 1 \\
\hline 4 & 53.15 & 1.5 & 0.175 & 0.560 & 0.816 & 1 & 1 \\
\hline 5 & 30.2 & 2.2 & 0 & 0 & 1 & 0.642 \\
\hline 6 & 30.2 & 2.2 & 0.316 & 0.613 & 0.919 & 0.825 & 0.760 \\
\hline
\end{tabular}

663 


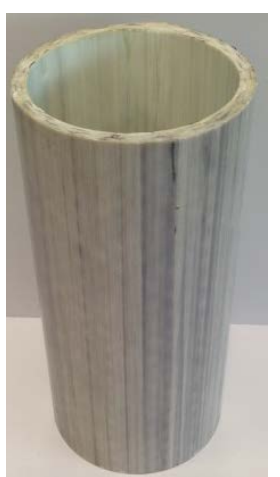

(a) Group A

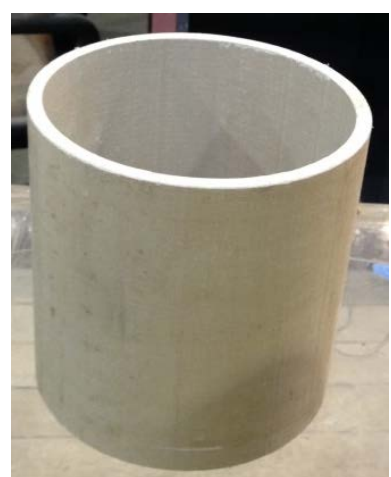

(b) Group B

Fig. 1. Intact GFRP tubes

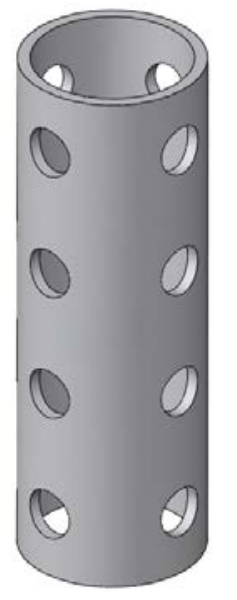

(a) APT

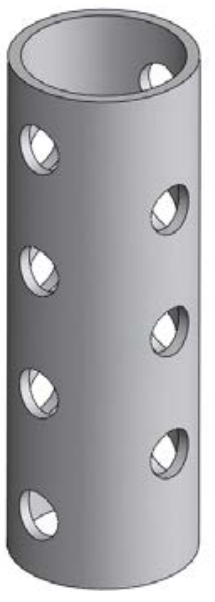

(b) DPT

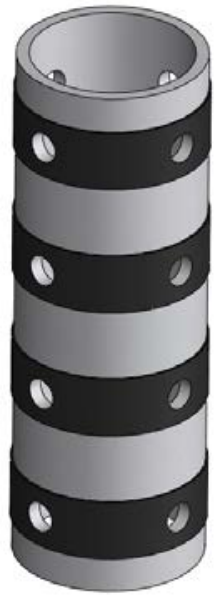

(c) APT-LW

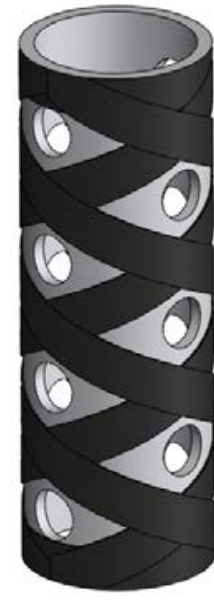

(d) DPT-LW

Fig. 2. Perforated GFRP tubes 


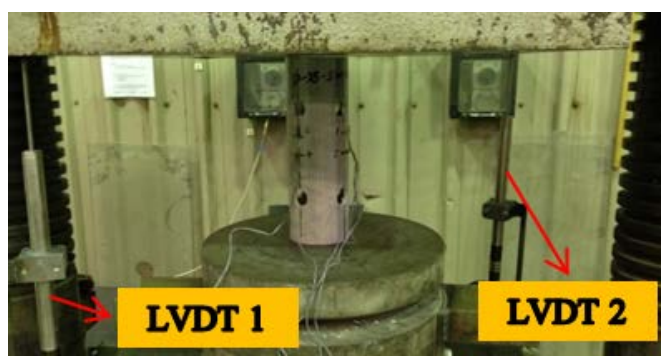

Fig. 3. Test setup and instrumentation

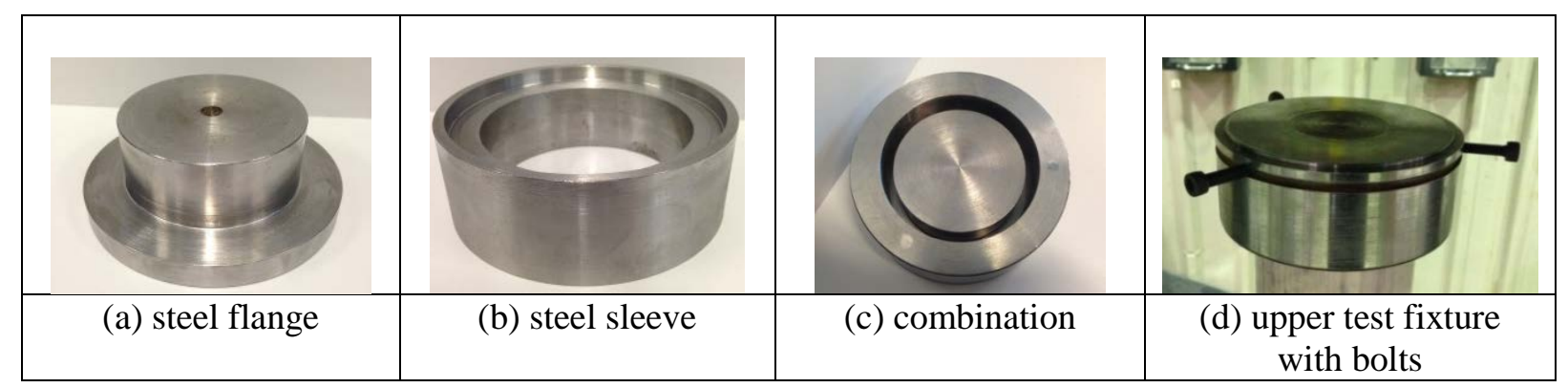

Fig. 4. Details of test fixture 


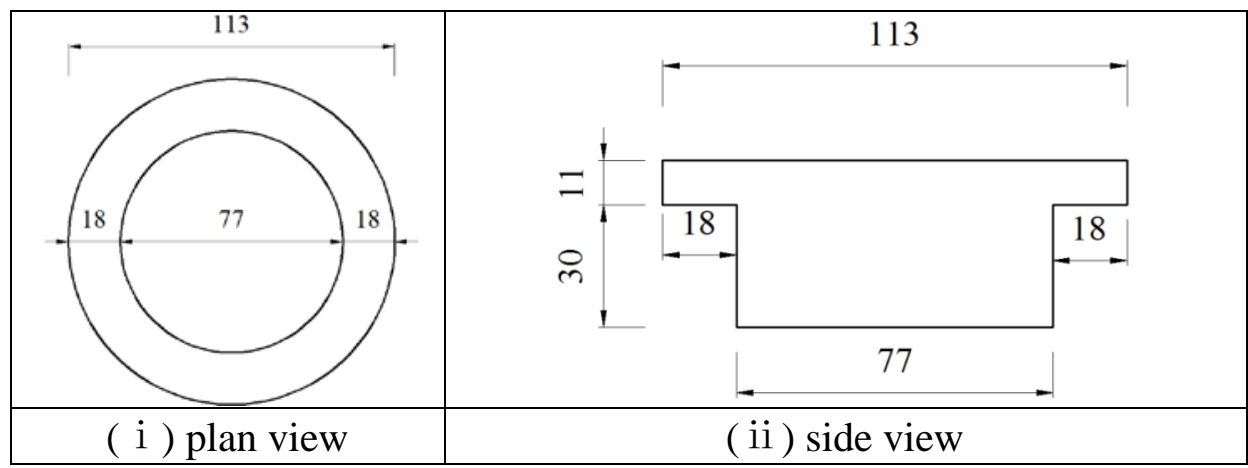

(a) steel flange

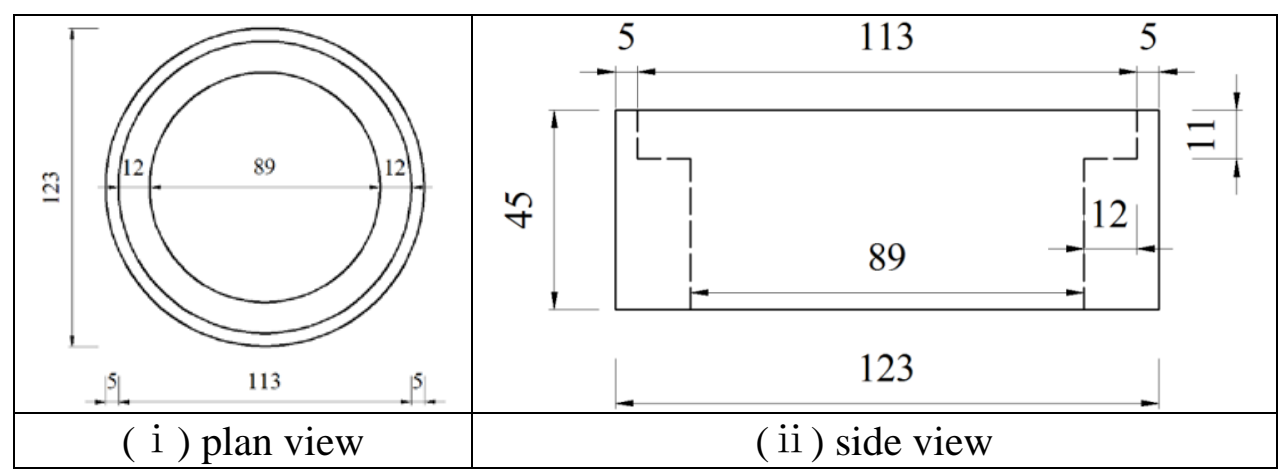

(b) steel sleeve

Fig. 5. Engineering drawings of test fixture 


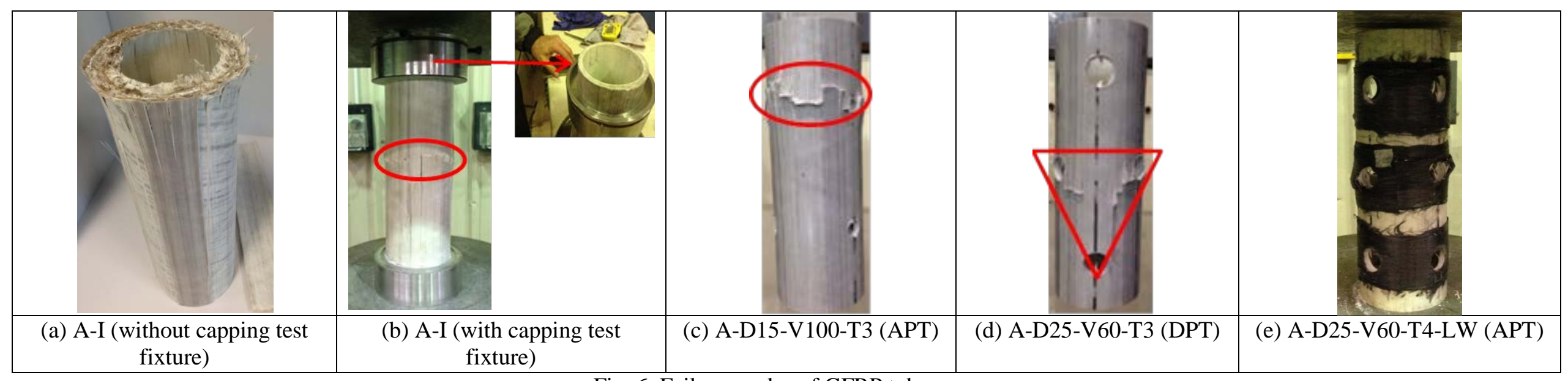

Fig. 6. Failure modes of GFRP tubes 


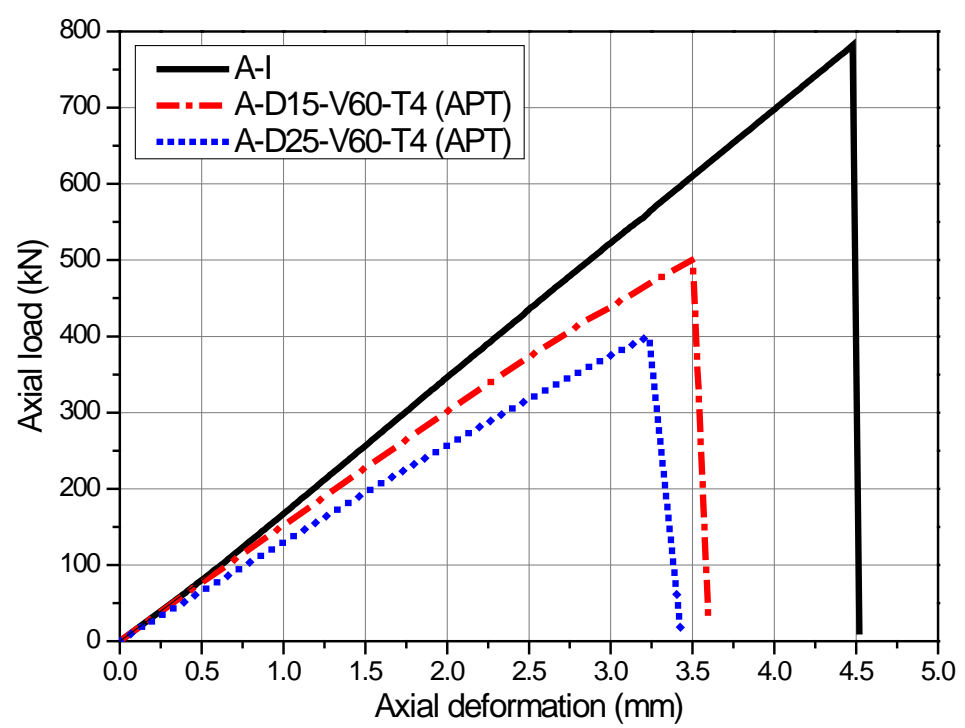

(a) Axial load-axial deformation behaviour of A-I, A-D15-V60-T4 (APT) and A-D25-V60-T4 (APT)

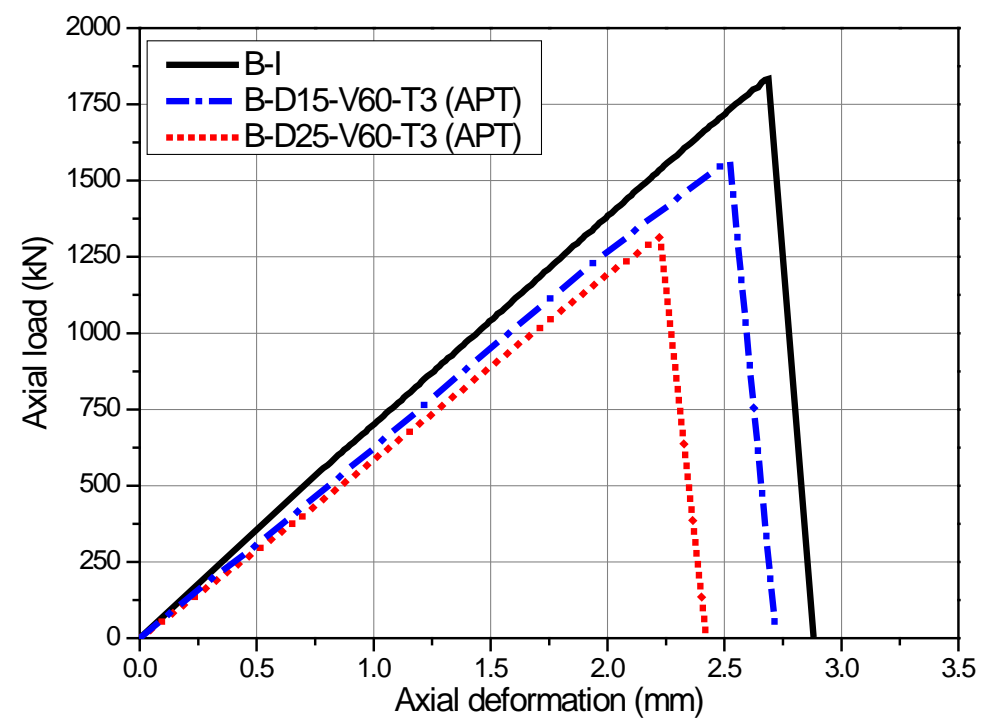

(b) Axial load-axial deformation behaviour of B-I, B-D15-V60-T3 (APT) and B-D25-V60-T3 (APT)

Fig. 7. Influence of hole diameter on the axial compressive behaviour of perforated GFRP tubes 

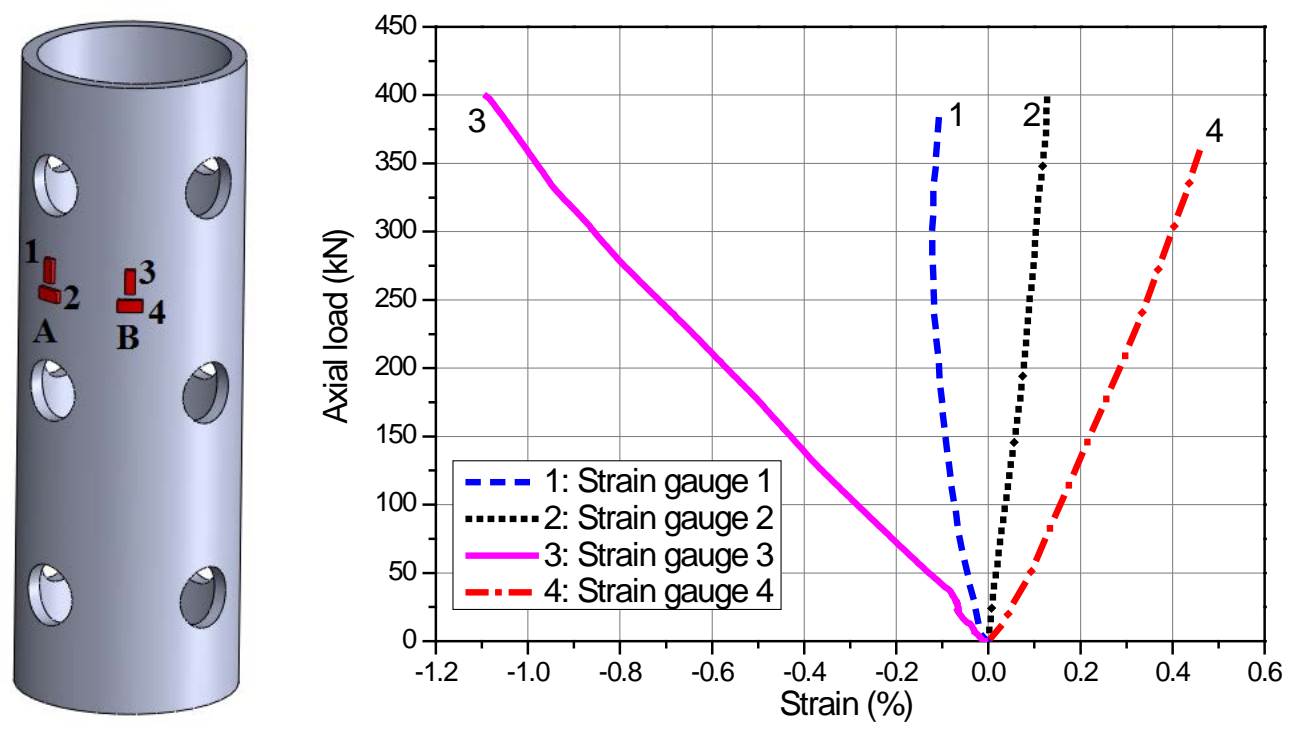

(a) Strain gauges layout

(b) Strain distribution

Fig. 8. Strain distributions at different locations of GFRP tube "A-D25-V60-T4 (APT)" 


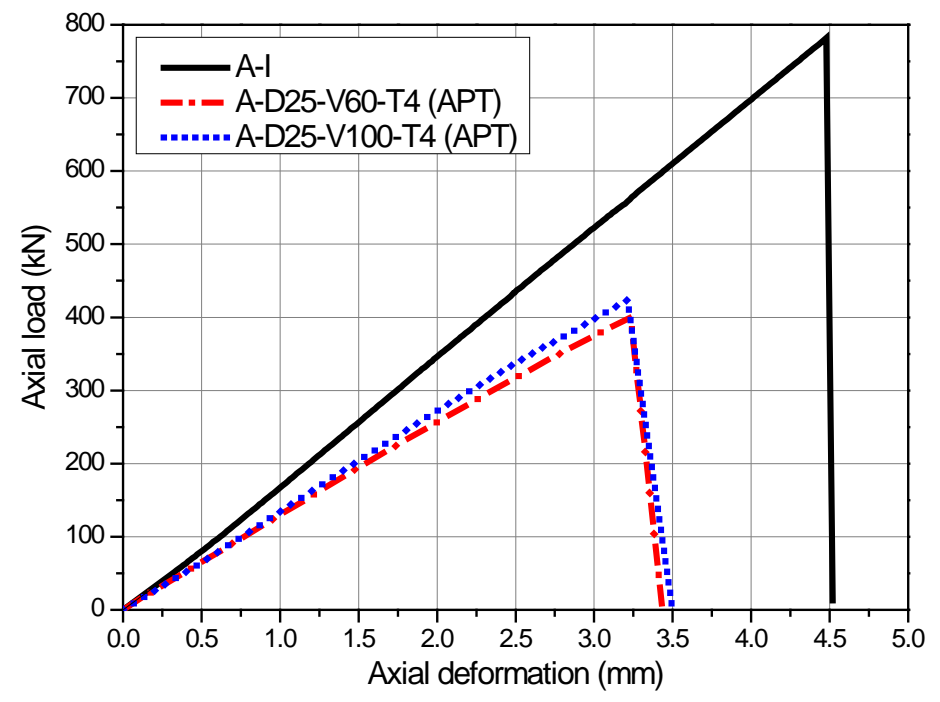

(a) Axial load-axial deformation behaviour of A-I, A-D25-V60-T4 (APT) and A-D25-V100-T4 (APT)

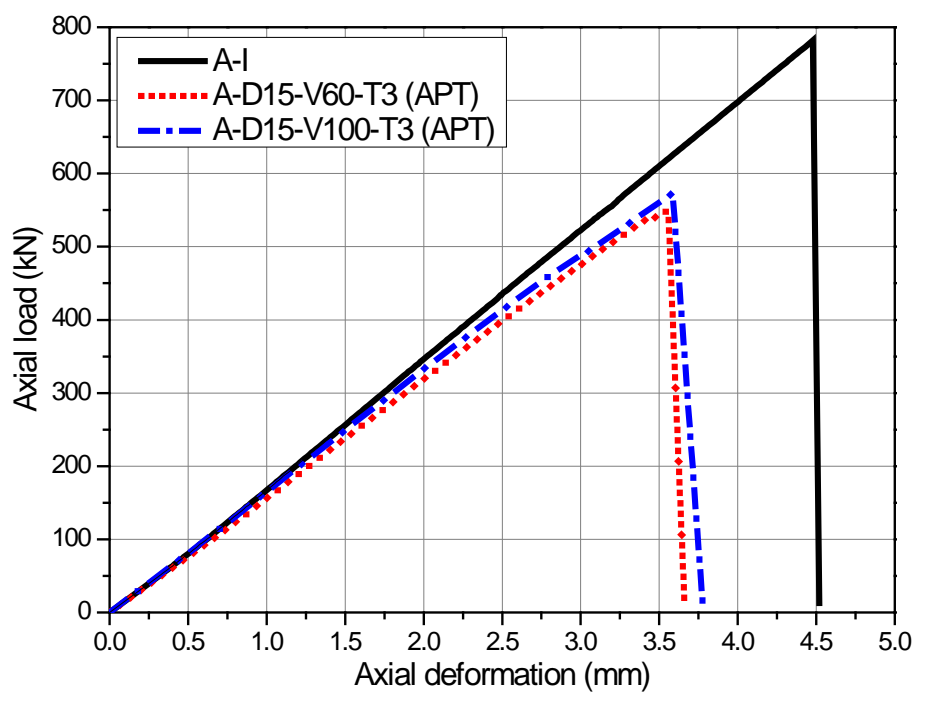

(b) Axial load-axial deformation behaviour of A-I, A-D15-V60-T3 (APT) and A-D15-V100-T3 (APT)

Fig. 9. Influence of vertical hole spacing on the axial compressive behaviour of perforated GFRP tubes 

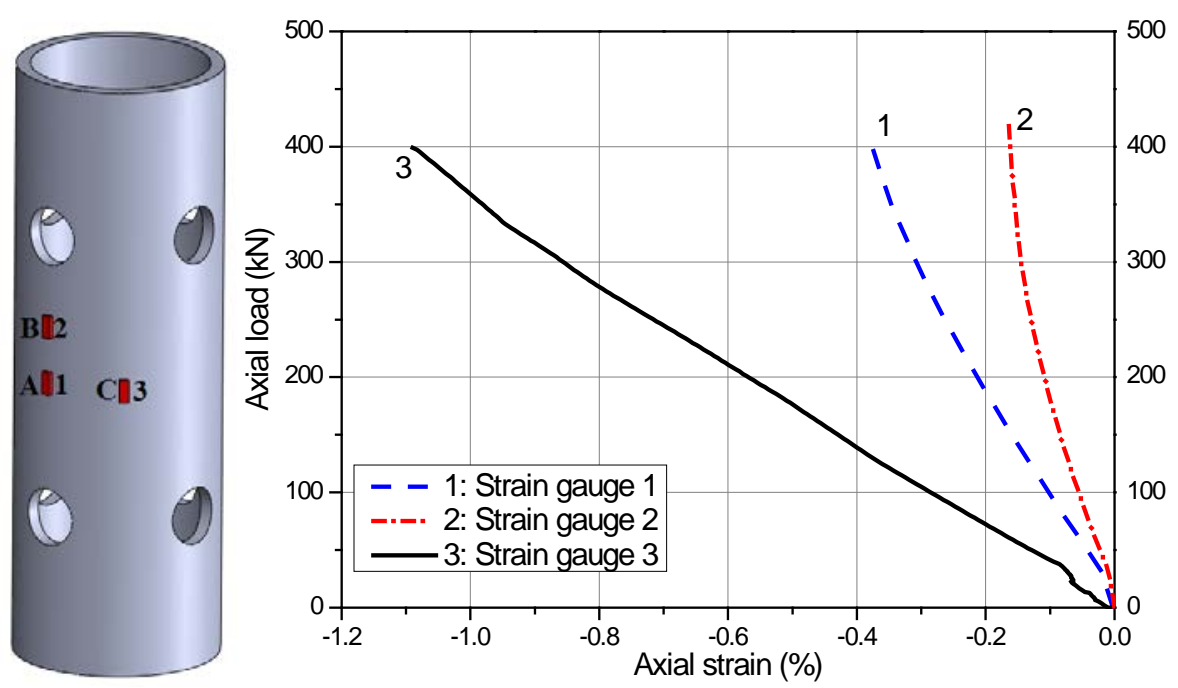

(a) Strain gauges layout

(b) Strain distribution

Fig. 10. Axial strains distributions at different locations of GFRP tube "A-D25-V100-T4 (APT)" 


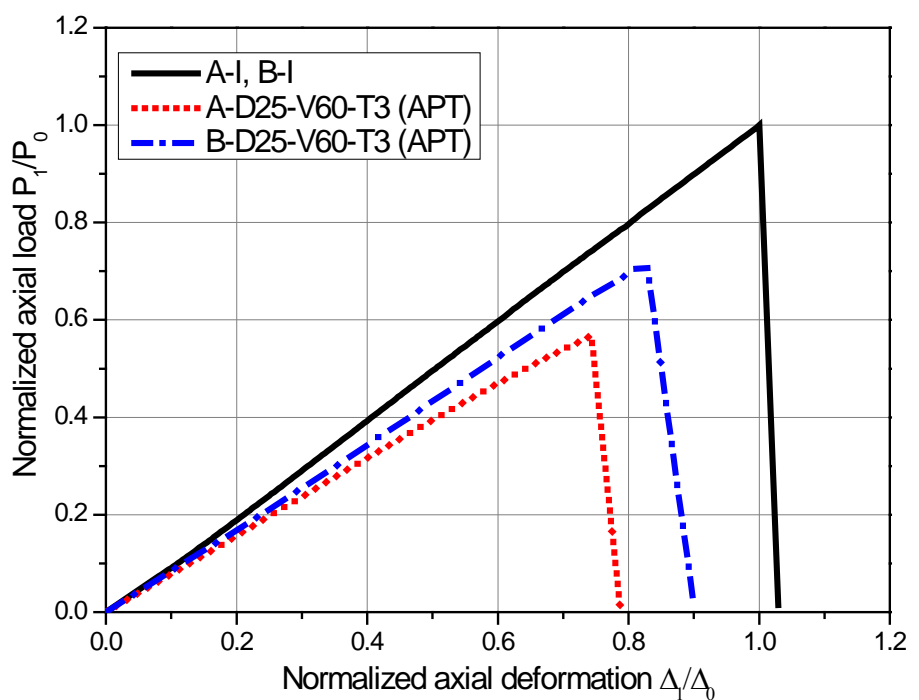

(a) Normalised axial load-axial deformation behaviour of A-I, B-I, A-D25-V60-T3 (APT) and B-D25-

V60-T3 (APT)

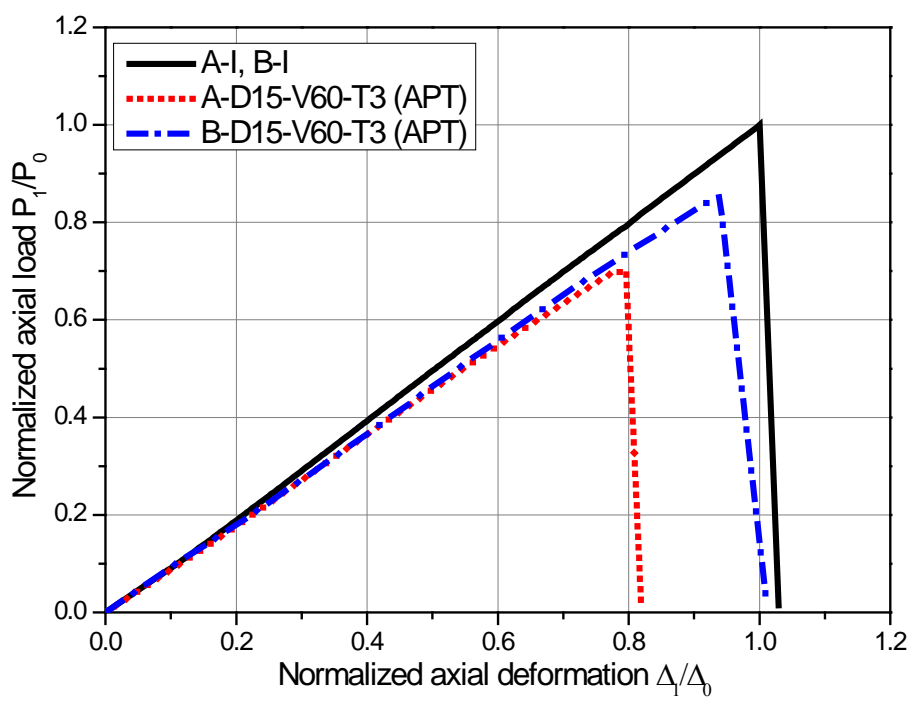

(b) Normalised axial load-axial deformation behaviour of A-I, B-I, A-D15-V60-T3 (APT) and BD15-V60-T3 (APT)

Fig. 11. Influence of tube diameter on the axial compressive behaviour of perforated GFRP tubes 


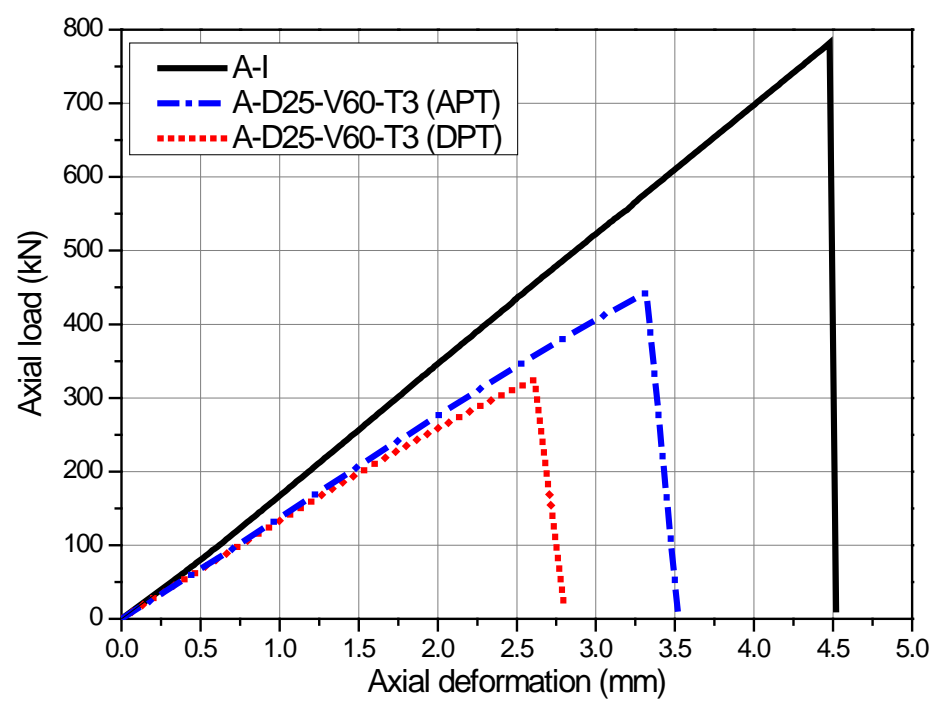

(a) Axial load-axial deformation behaviour of A-I, A-D25-V60-T3 (APT) and A-D25-V60-T3 (APT)

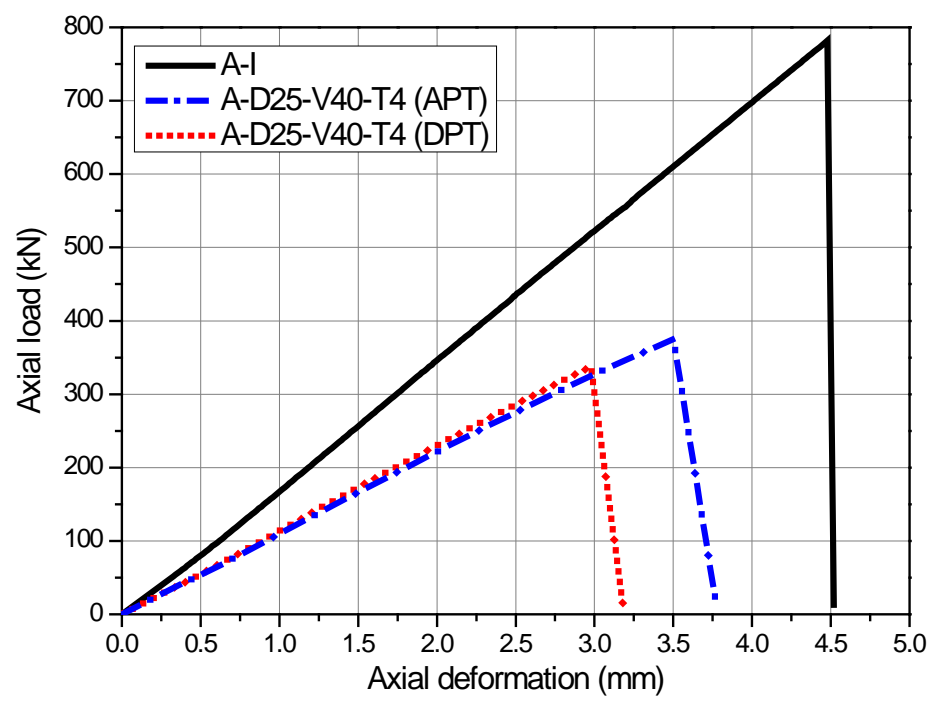

(b) Axial load-axial deformation behaviour of A-I, A-D25-V40-T4 (APT) and A-D25-V40-T4 (APT)

Fig. 12. Influence of perforation pattern on the axial compressive behaviour of perforated GFRP tubes 


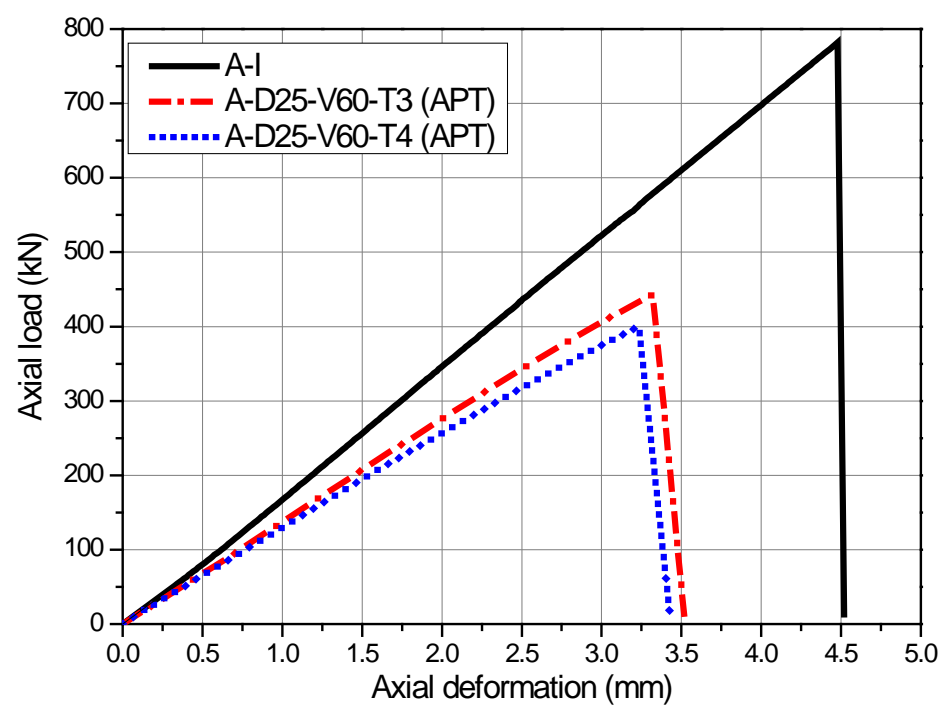

(a) Axial load-axial deformation behaviour of A-I, A-D25-V60-T3 (APT) and A-D25-V60-T4 (APT)

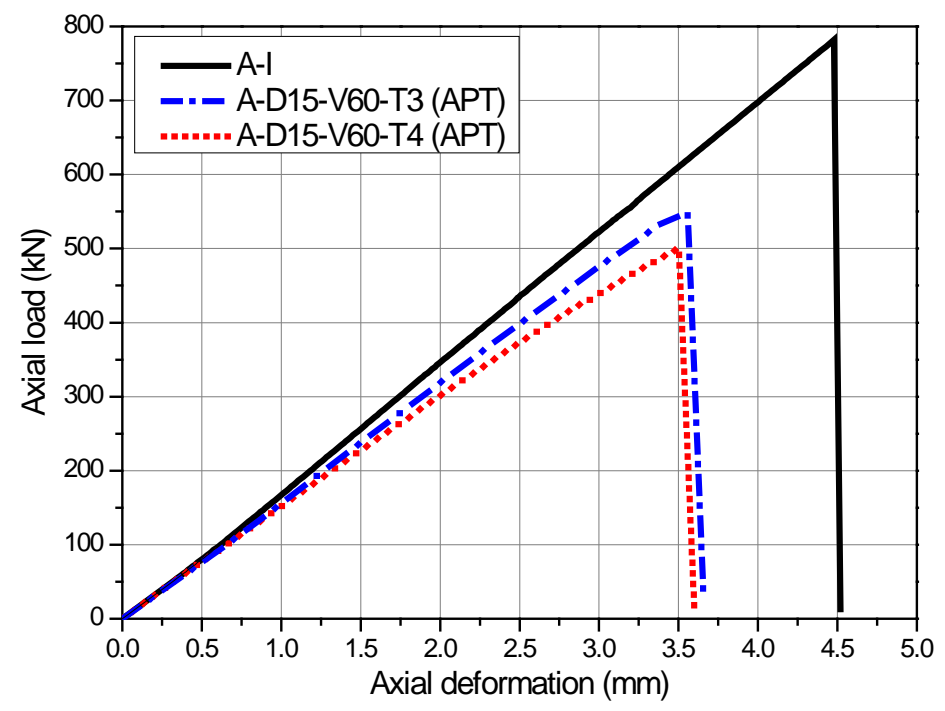

(b) Axial load-axial deformation behaviour of A-I, A-D15-V60-T3 (APT) and A-D15-V60-T4 (APT)

Fig. 13. Influence of transverse hole spacing on the axial compressive behaviour of perforated GFRP tubes 


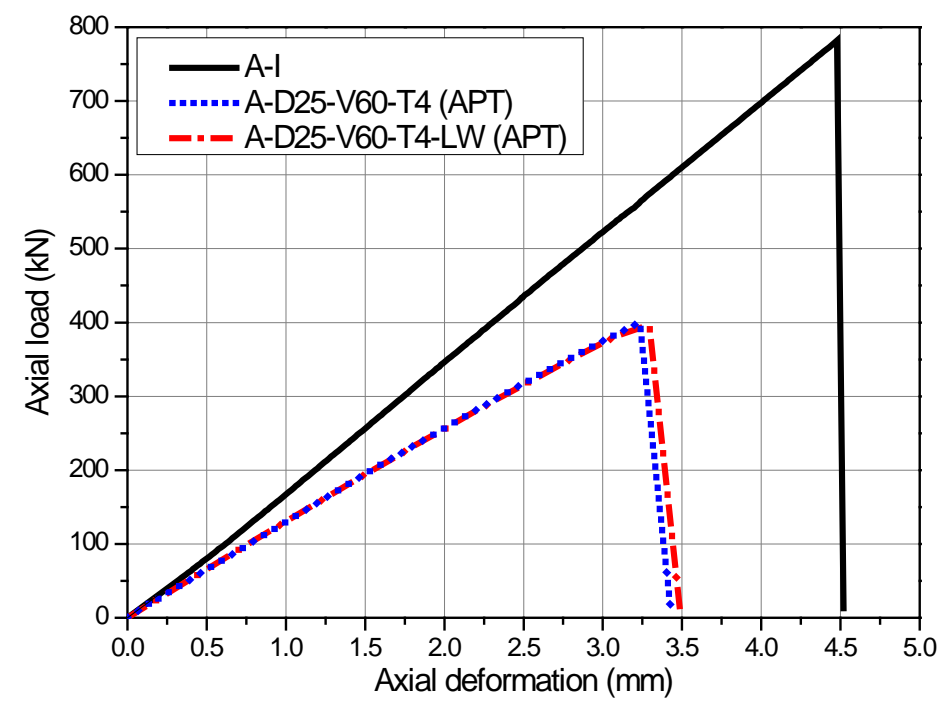

(a) Axial load-axial deformation behaviour of A-I, A-D25-V60-T4 (APT) and A-D25-V60-T4-LW (APT)

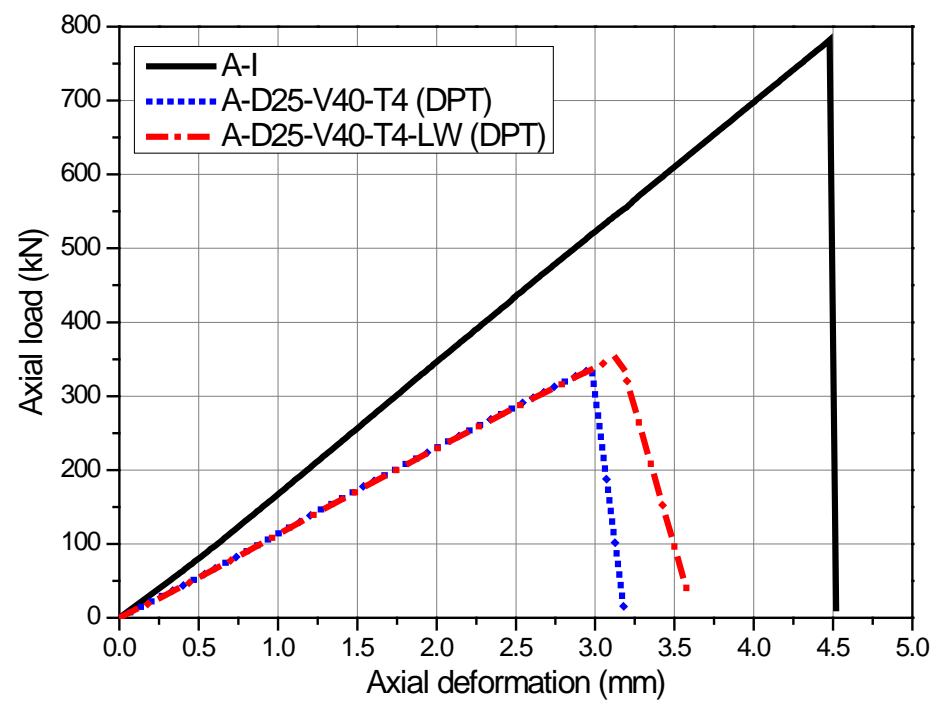

(b) Axial load-axial deformation behaviour of A-I, A-D25-V40-T4 (DPT) and A-D25-V40-T4-LW (DPT)

Fig. 14. Influence of hole reinforcement on the axial compressive behaviour of perforated GFRP tubes 


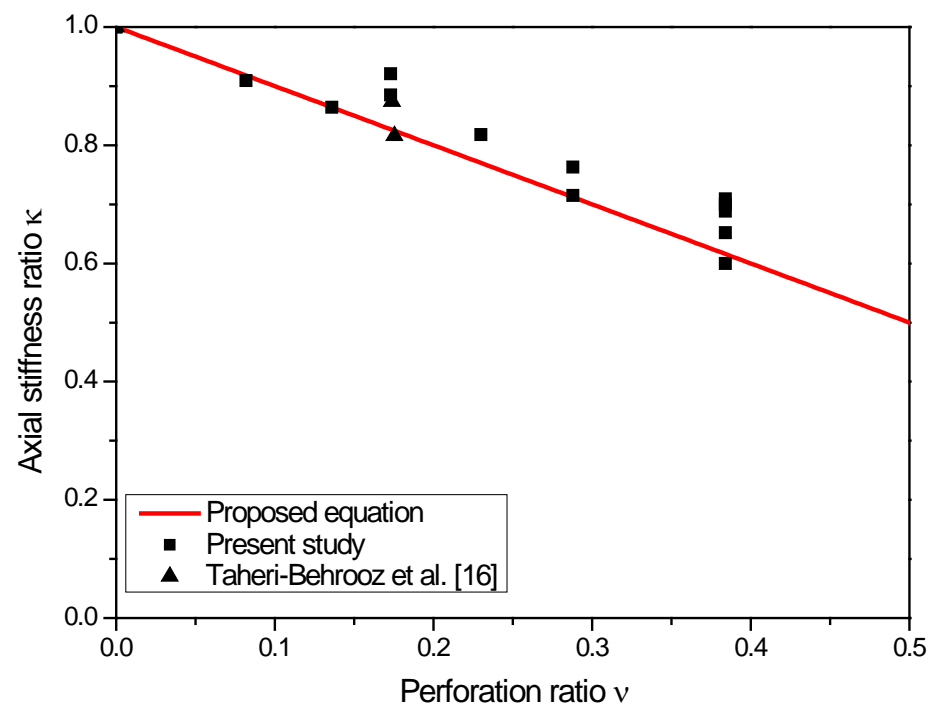

Fig. 15. Prediction of axial stiffness ratio from perforation ratio

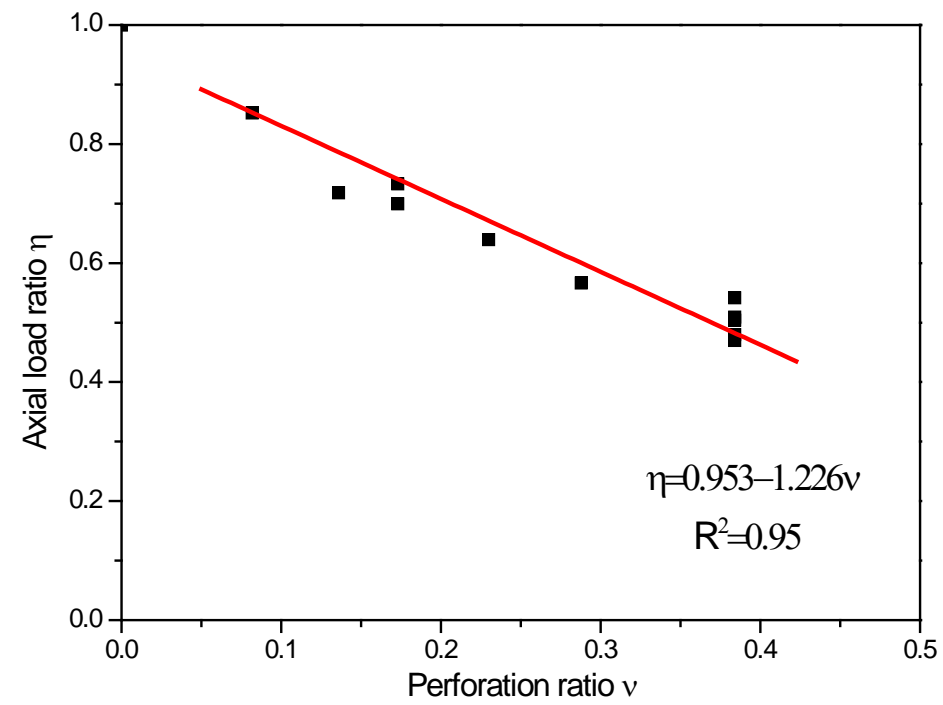

Fig. 16. Prediction of axial critical load ratio from perforation ratio (axially perforated GFRP tubes) 


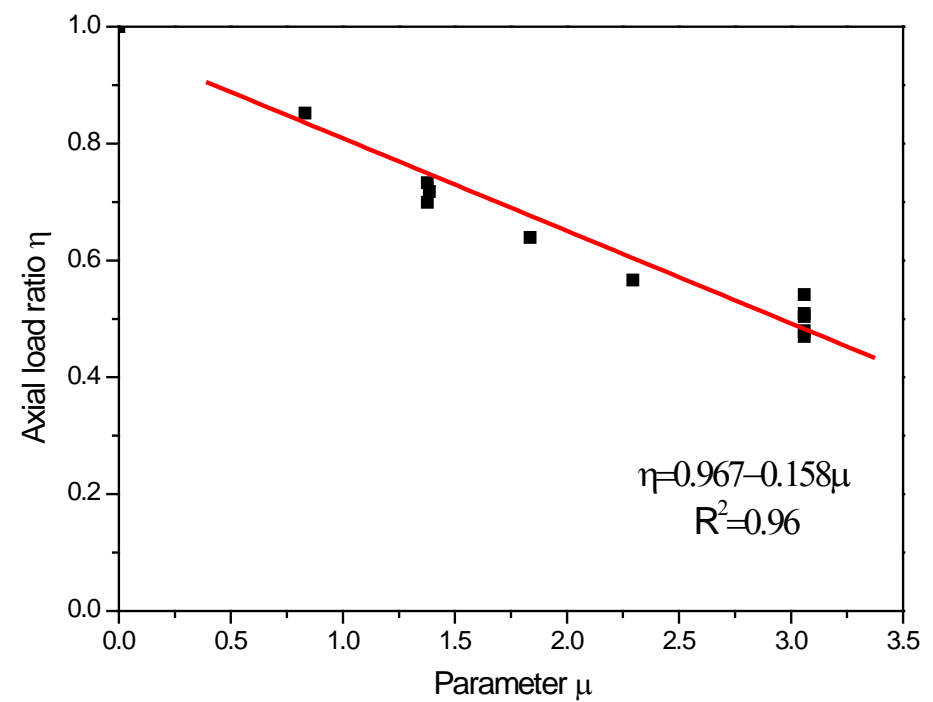

Fig. 17. Prediction of axial critical load ratio from parameter $\mu$ (axially perforated GFRP tubes)

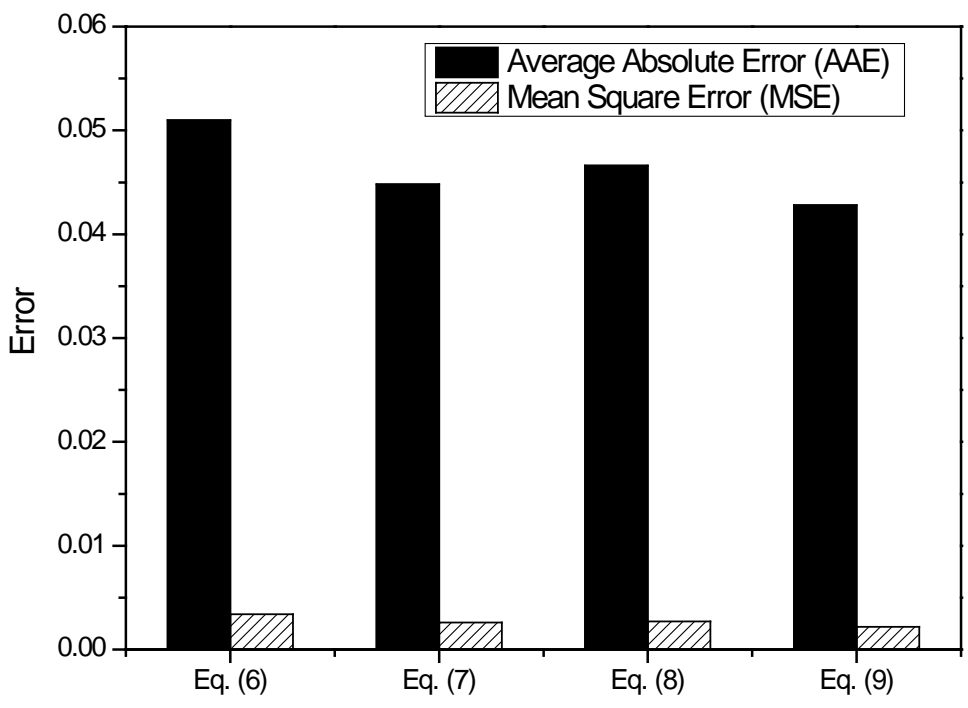

Fig. 18. Error estimates of the proposed design-oriented equations 


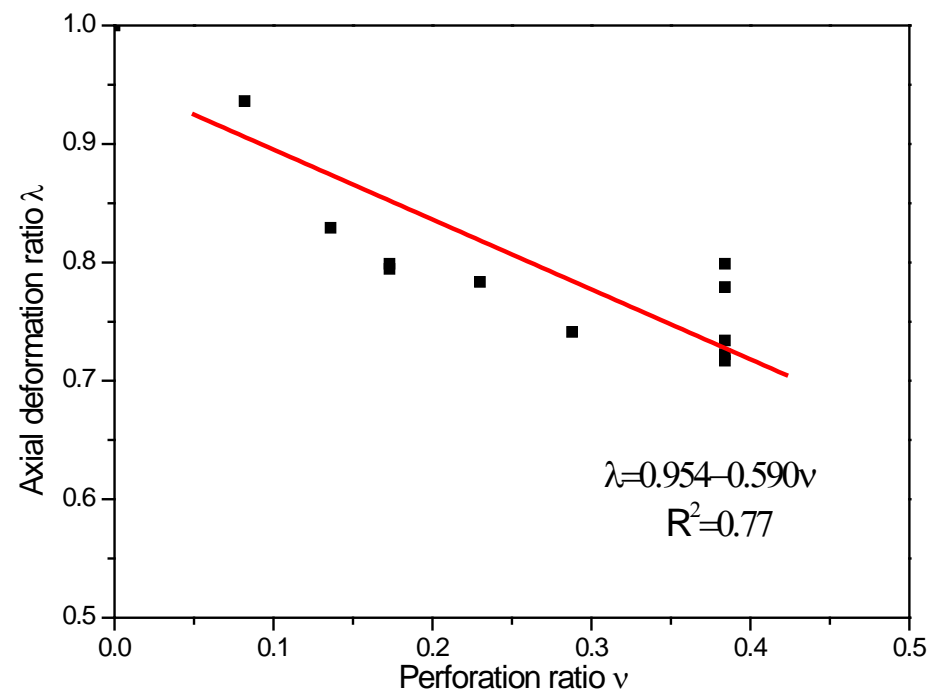

Fig. 19. Prediction of axial deformation ratio from perforation ratio (axially perforated GFRP tubes)

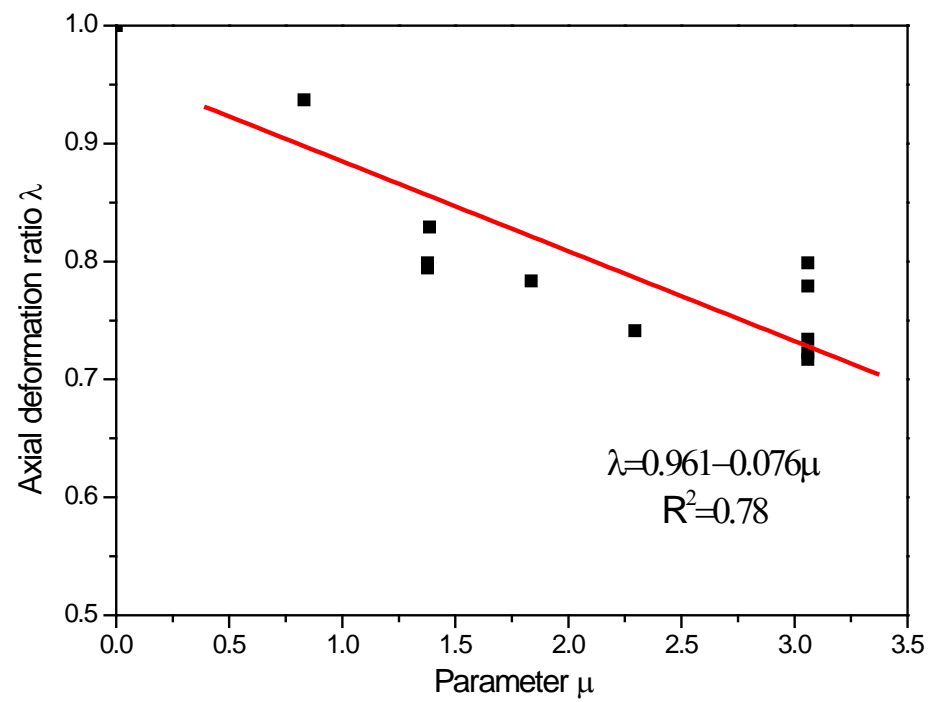

Fig. 20. Prediction of axial deformation ratio from parameter $\mu$ (axially perforated GFRP tubes) 